ISSN: 0514-7336

DOI: http://dx.doi.org/10.14201/zephyrus2015761538

\title{
DEL CALCOLÍTICO AL BRONCE ANTIGUO EN EL GUADALQUIVIR INFERIOR. EL CERRO DE SAN JUAN (CORIA DEL RÍO, SEVILLA) Y EL 'MODELO DE REEMPLAZO'
}

\section{From the Copper Age to the Bronze Age in the Lower Guadalquivir Basin. The Cerro de San Juan settlement (Coria del Río, Seville, Spain) and the 'replacement model'}

\author{
Daniel García Rivero y José Luis Escacena Carrasco
}

Dpto. de Prehistoria y Arqueología. Facultad de Geografía e Historia. Cl Doña María de Padilla, s/n. 41004 Sevilla.Correo-e:garciarivero@us.es; escacena@us.es

Recepción: 23/03/2015; Revisión: 6/07/2015; Aceptación: 20/09/2015

BIBLID [0514-7336 (2015) LXXVI, julio-diciembre; 15-38]

\begin{abstract}
Resumen: La transición Calcolítico-Bronce en el so ibérico es aún mal conocida, sobre todo si se compara con el paso de la Cultura de Los Millares a la del Argar en el SE. El asentamiento del Cerro de San Juan, que controlaba en esos momentos la paleodesembocadura del Guadalquivir, presenta ocupaciones de ambas etapas, rasgo poco frecuente en la zona. Los datos rescatados en este sitio sugieren una ruptura sedimentaria entre los dos momentos, a la vez que un fuerte cambio cultural. Un repertorio material distinto caracteriza bien cada fase, la campaniforme y la del Bronce; asimismo, varias dataciones radiocarbónicas coherentes definen la cronología del fenómeno. Desde este punto de vista, se realiza un análisis de todas las estratigrafías arqueológicas que cuentan con evidencias de ambos periodos. Frente a un 'modelo de continuidad', numerosos rasgos arqueológicos sugieren más bien un 'modelo de reemplazo'. El Bronce antiguo puede definirse, pues, como un nuevo sistema de vida protagonizado tal vez por grupos que no eran herederos directos de las comunidades precedentes.

Palabras clave: Edad del Cobre; Edad del Bronce; tradición; cambio cultural; Andalucía; cerámica campaniforme.
\end{abstract}

Abstract: The transition between Copper and Bronze Ages in the Southwest of the Iberian Peninsula is poorly known still, especially when compared with the transition between Los Millares culture to El Argar culture in the Southeast. The settlement of Cerro de San Juan, which controlled the Guadalquivir mouth at that time, shows some evidences of human occupations of both periods, an uncommon feature along the South of Iberian Peninsula. The data from this site suggest a sedimentary break between the two periods, and a strong cultural change as well. The culture material sets are different between the Bell Beaker phase and the Bronze Age, and several radiocarbon dates define consistently the chronology of the phenomenon. From this perspective, an analysis of every archaeological stratigraphy that has evidences of both periods is carried out. Against a model of cultural continuity, numerous archaeological features rather suggest a model of demographic replacement. Thus, the Bronze Age can be defined as a new way of life perhaps by human groups that were not direct descendants of the previous communities.

Key words: Copper Age; Bronze Age; cultural tradition; cultural change; Andalusia; bell beaker pottery.

(C) Universidad de Salamanca

Zephyrus, LXXVI, julio-diciembre 2015, 15-38 


\section{Introducción ${ }^{1}$}

Existe cierto desconocimiento general sobre el paso de la Edad del Cobre a la del Bronce en el mediodía hispano. Según las fechas radiocarbónicas disponibles, se han documentado numerosos asentamientos calcolíticos ocupados hasta aproximadamente el cambio entre los milenios III y II a. C.; también se han registrado yacimientos del Bronce antiguo, mucho más escasos y con fechas iniciales coetáneas o ligeramente posteriores ( $c f$. Mederos, 1996; Hunt et al., 2008; García Sanjuán y Hurtado, 2011).

El registro arqueológico calcolítico del so de la Península Ibérica muestra grosso modo poblaciones variables en tamaño, con superficies que van desde apenas 1 ha a cientos de ellas. Se trata de una ocupación densa del territorio que muestra una preferencia especial por valles de ríos y campiñas fértiles, sin que ello suponga un vacío de hábitats en áreas de montaña. Los datos disponibles hablan sobre todo de economías de base agropecuaria con aprovechamiento de sus productos derivados (Harrison y Moreno, 1985; Morales, 1986; García Rivero, 2005). Tales grupos humanos cuentan con un mundo simbólico donde predominan estructuras funerarias con inhumaciones múltiples, numerosas expresiones rupestres de arte esquemático y abundantes figurillas que, con el nombre genérico de 'ídolos', se han relacionado normalmente con creencias religiosas.

Frente a este panorama, el Bronce antiguo se caracteriza por asentamientos muy pequeños -en torno a 1 ha o menos de superficie-, además de mucho más dispersos en el territorio. De hecho, se trata de sitios bastante uniformes en extensión, lo que dificulta observar una clara jerarquización entre ellos. Estos lugares se distribuyen también por ecosistemas heterogéneos, tanto litorales como de campińa o de sierra. No obstante, la presencia de murallas en algunos asentamientos hace sospechar que hubiese centros más extensos y potentes. Es el caso, por ejemplo, del Cerro del Castillo, en Alcalá de Guadaíra (Pozo y Tabales, 1991: 540-541). Para algunos autores, en ciertas comarcas del sur hispano este mundo de comienzos del

1 Este trabajo se ha realizado en el marco del grupo de investigación Tellus: Prehistoria y Arqueología en el Sur de Iberia (Hum-949 del PAIDI), radicado en la Univ. de Sevilla. Estamos en deuda con J. M. Román Rodríguez, del Servicio de Arqueología del Ayto. de Carmona, por habernos suministrado interesantes datos aún inéditos sobre este asentamiento.
II milenio a. C. conoció una economía de espectro menos amplio que la de la etapa calcolítica anterior, con una vertiente pastoril más señalada que para el milenio anterior (Harding, 2003; Lull et al., 2010). Pero este rasgo no puede hacerse extensivo de forma automática a todo el mediodía ibérico; sí en cambio el carecer de representaciones simbólicas tan explícitas como las que caracterizan a la Edad del Cobre. De hecho, ahora desaparecen los 'idolillos' y disminuyen notablemente las representaciones de arte rupestre. En el so hispano, los nuevos ritos funerarios están caracterizados fundamentalmente por inhumaciones, casi siempre individuales. Los enterramientos se practican en fosas y cistas que conforman necrópolis, muchas veces bien diferenciadas de los asentamientos (Del Amo, 1975; Fernández Gómez et al., 1976; Escacena y De Frutos, 1986; Pérez Macías, 1997; Hunt, 2012). Pero también se han documentado sepulturas en el interior de los poblados (Aubet y Serna, 1981; Escacena y De Frutos, 1981-1982).

A pesar del fuerte contraste cultural entre ambos periodos, fácilmente captable en el registro arqueológico, apenas existen hipótesis históricas para el oeste andaluz sobre los porqués de este notable cambio, que se manifiesta con toda su fuerza también en la alfarería. Entre las escasas explicaciones disponibles está la que ha visto en las condiciones climáticas el factor principal. De hecho, hacia comienzos del II milenio a. C. se ha instalado en la Península Ibérica un ambiente marcadamente más árido que el inmediatamente anterior (Cacho et al., 2010: 19-20). Esta causa no ha sido trabajada para el cuadrante suroccidental de la Península Ibérica, aunque sí para la zona sureste de forma más profunda (Bellin et al., 2013). En este segundo entorno, árido por su escasa pluviosidad, la agricultura habría requerido prácticas de irrigación, desembocando en la necesidad de infraestructuras y de una compleja gestión; y éstas, a la larga, en el aumento de la desigualdad social (Chapman, 1990). Si algo se ha dicho al respecto sobre el cuadrante suroccidental hispano es que esta tendencia a la sequedad del clima fue aquí más marcada incluso que en otras zonas, como revelan los registros paleohidrológicos (Martín-Puertas et al., 2008).

El se de la Península Ibérica cuenta con una historiografía más abundante en cuanto al estudio del Bronce antiguo, esencialmente debido a los numerosos sitios de la cultura argárica conocidos desde hace tiempo. En el caso de la baja Andalucía, aparte de 
los enterramientos en cistas y fosas más occidentales conocidos desde hace décadas en las provincias de Huelva y Sevilla, y de los sevillanos y gaditanos de interior de poblado, se vienen excavando en los últimos años algunos yacimientos que empiezan a arrojar un poco más de luz sobre este periodo (Hurtado et al., 2011; Hunt et al., 2008; Hunt, 2012; Ramos, 1993). Además, apenas existen estratigrafías verticales que cuenten con niveles calcolíticos directamente infrapuestos a los del Bronce ntiguo, como luego veremos, siendo Carmona (Belén et al., 2000: 386) -y ahora Coria del Río- unas de las pocas excepciones a esta situación (Fig. 1).

¿Qué significa esta escasez de evidencias a favor de la continuidad cultural entre el Calcolítico y el Bronce del s ibérico? ¿Qué puede aceptarse entre ambas fases, evolución o ruptura? A estas preguntas puede contestarse con dos explicaciones distintas, sin que tengan que ser necesariamente excluyentes: a) que se asistió a un acelerado y profundo proceso de cambio en el seno de una misma población -'modelo de continuidad'- y b) que se produjo la sustitución de grupos

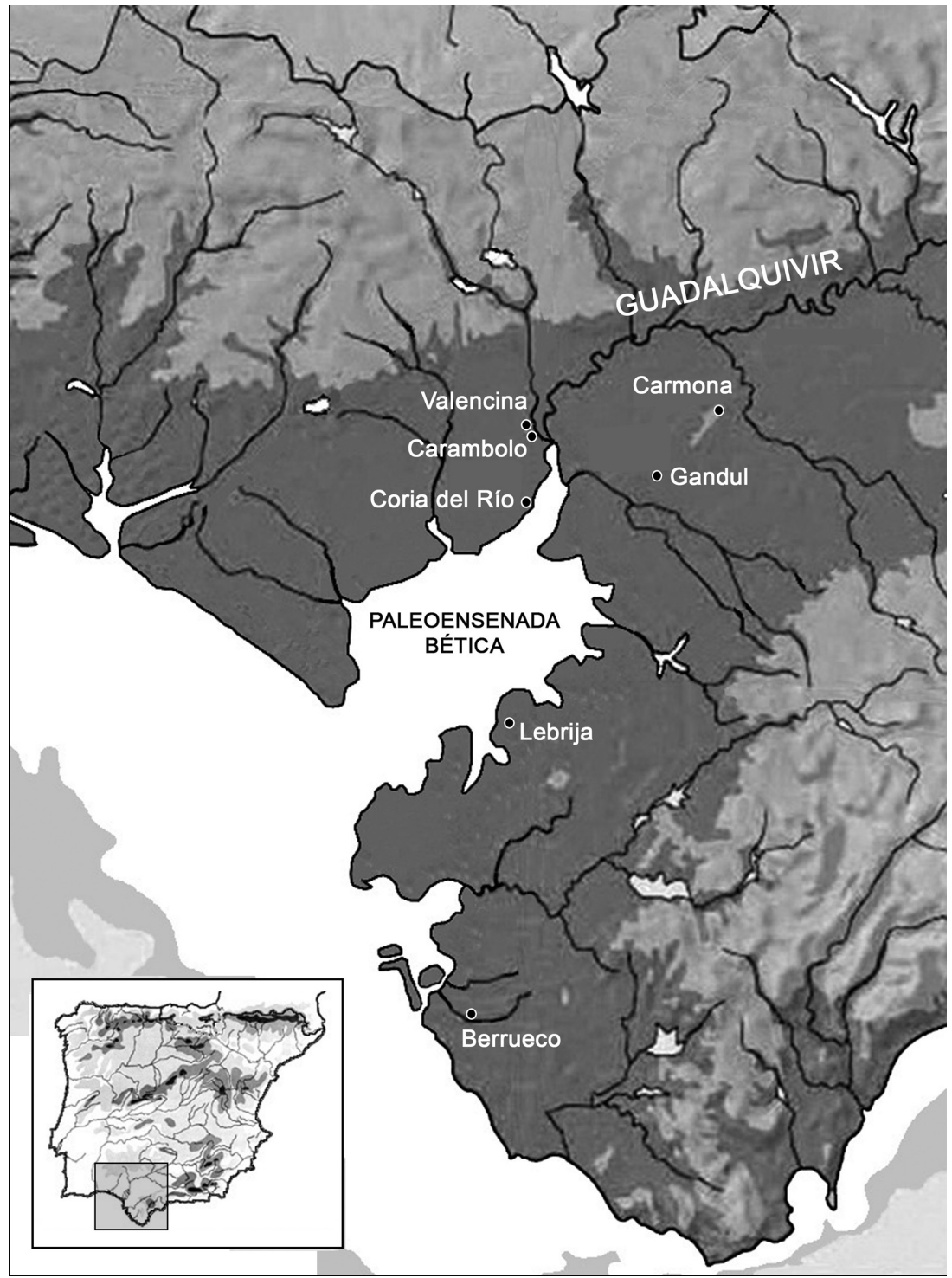

FIG. 1. Localización en el Guadalquivir inferior de los sitios arqueológicos discutidos en el texto con superposición de estratos de la Edad del Cobre y de la Edad del Bronce. diferentes -'modelo de reemplazo'-. Ambos patrones podrían haber coexistido en el territorio, aunque tal vez no en un mismo asentamiento. Su constatación requiere evidencias arqueológicas diversas, cuyas huellas deberían ser detectables en los yacimientos. En la antigua desembocadura del Guadalquivir, unos $10 \mathrm{~km}$ al s de Sevilla, el Cerro de San Juan de Coria del Río ha suministrado interesantes datos para analizar este episodio histórico. Tales evidencias podrían dar más apoyo a la segunda hipótesis que a la primera.

\section{Objetivos}

El objetivo del presente estudio es analizar detalladamente una de las pocas secuencias estratigráficas verticales que en Andalucía occidental cuentan con materiales calcolíticos y del Bronce antiguo en sendos estratos superpuestos, en busca de datos que permitan evaluar los dos modelos anotados -'continuidad' vs. 'reemplazo'-. Se trata del cabezo que, con el nombre de Cerro de San Juan, supone el emplazamiento de la 


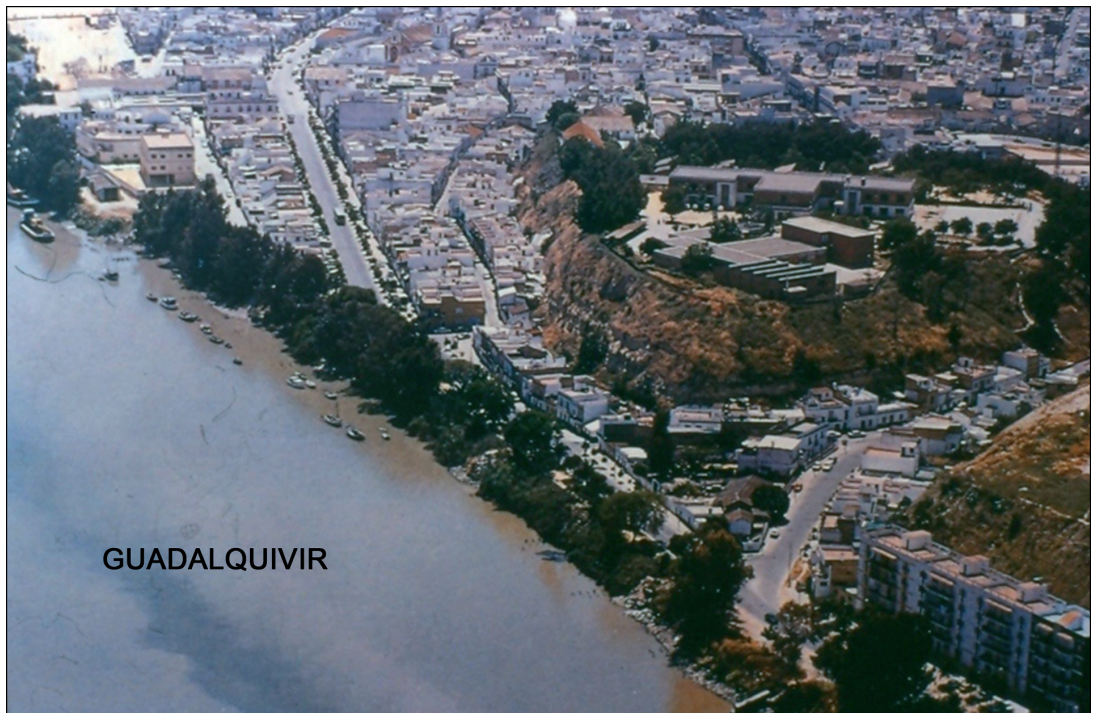

Fig. 2. Vista del Cerro de San Juan (Coria del Río) desde el N, jalonando el río Guadalquivir por su margen derecha.

Por último, se discuten todas estas evidencias halladas en el Cerro de San Juan y en la zona de Andalucía occidental, y se concluye cuál de los dos modelos teóricos propuestos está más sustentado en relación con la transición Calcolítico-Bronce en el s ibérico.

\section{Datos y métodos}

Se presenta a continuación una síntesis sobre el yacimiento arqueológico del Cerro de San Juan, que hasta ahora se conoce más en la literatura arqueológica por su fase protohistórica que por la prehistórica. Igualmente, se describen los contextos estratigráficos de los dos momentos que ahora importan

posterior Caura protohistórica y romana, así como de la actual localidad sevillana de Coria del Río (Fig. 2).

Se analiza aquí la estratigrafía y se estudian sus materiales arqueológicos. Con la excepción de aquellos restos que pueden considerarse elementos residuales porque aparecen fuera de sus contextos primarios a causa de remociones postdeposicionales, los elementos calcolíticos y del Bronce antiguo caracterizan respectivamente a los dos estratos inferiores de la secuencia-E-I y E-II, por el orden cronológico en que se depositaron-, pues el III, inmediatamente encima, es ya de época tartésica y plantea problemas no relacionables con la temática aquí planteada. Además del análisis estratigráfico, presentamos los testimonios cerámicos más representativos de estas dos fases y cuantificamos todos sus materiales diagnósticos. Por otra parte, hemos obtenido dataciones radiocarbónicas en muestras procedentes de ambos estratos.

Posteriormente se realiza una revisión detallada de las secuencias arqueológicas que en Andalucía occidental cuentan con estratos fechados en ambos periodos arqueológicos. Asimismo se consideran las fechas radiocarbónicas -cuyas calibraciones actualizamos- disponibles actualmente no sólo para dichas secuencias, sino también para los asentamientos calcolíticos o del Bronce antiguo que cuentan con dataciones en el Guadalquivir inferior y zonas adyacentes. y se muestra una representación sucinta de la documentación arqueológica que los caracteriza.

\subsection{El yacimiento: ubicación y rasgos básicos}

En el tercer milenio a. C., la desembocadura del Guadalquivir se encontraba en las proximidades de las poblaciones sevillanas de Coria y La Puebla del Río. La arteria fluvial conectaba en este punto con la paleoensenada bética, un golfo que ocupaba la actual comarca de Las Marismas. Esta antigua línea de costa ha sido confirmada por diversos estudios geoarqueológicos (Menanteau, 1982; Arteaga et al., 1995), que han seguido recientemente a otros análisis de carácter geológico de mediados del s. xx (Gavala, 1959). Las reconstrucciones hipotéticas del entorno permiten sospechar que, junto a la ladera suroeste del Cerro de San Juan, existía además un pequeño refugio delimitado por la desembocadura del Pudio, hoy afluente del Guadalquivir por la derecha y entonces pequeño arroyo independiente. Este sector disponía de buenas condiciones portuarias, pero no está confirmado su uso como embarcadero en época prehistórica. En cualquier caso, se desconocen detalles más precisos de la morfología de la costa en estos momentos. El 
mapa indica, de todas formas, la importancia estratégica del lugar. Con posterioridad, la desembocadura del Guadalquivir fue desplazándose hacia el sur hasta alcanzar su ubicación actual en Sanlúcar de Barrameda (Borja, 2013).

El Cerro de San Juan es una pequeña meseta del borde oriental de la comarca sevillana del Aljarafe. Hoy cuenta con casi $27 \mathrm{msnm}$, pero al inaugurarse como hábitat humano estable disponía de menos altura. De hecho, sobre el sustrato geológico se acumulan hoy en algunos puntos hasta $6,5 \mathrm{~m}$ de relleno arqueológico. La corona actual del promontorio es prácticamente horizontal, aunque se le ha proporcionado un perfil escalonado en el s. xx. El testimonio más viejo de una posible ocupación corresponde al Neolítico (Gavilán y Escacena, 2009: 345). En sentido estricto, la fase prehistórica del Cerro de San Juan se inicia sobre los restos de una terraza del Guadalquivir de arcillas rubefactadas con abundantes cantos rodados de cuarcita. Sobre este suelo geológico se acumula un primer estrato de fecha campaniforme y otro posterior del Bronce antiguo; y sobre ellos una potente secuencia sedimentaria de época tartésica,

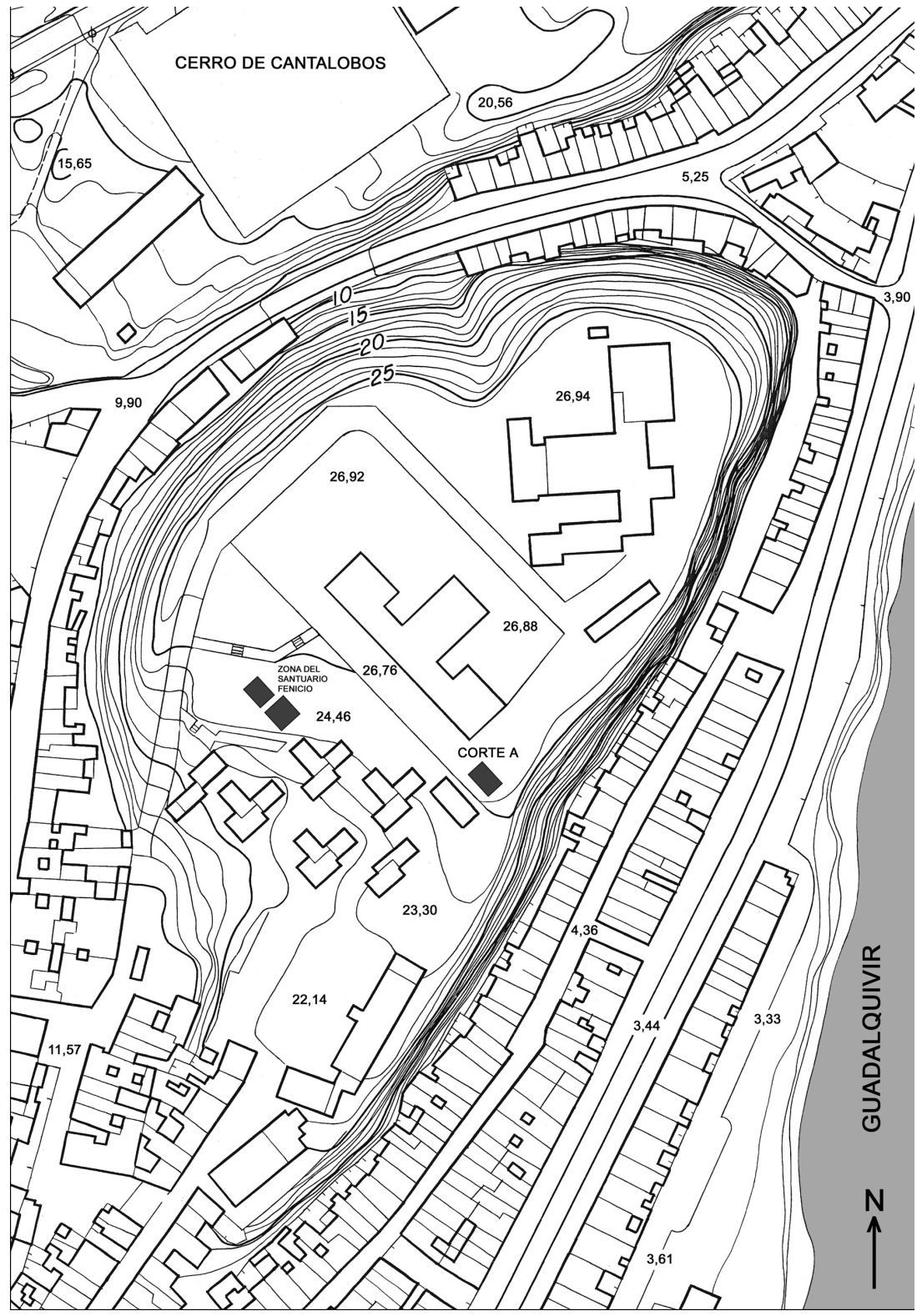

FIG. 3. Ubicación del Corte A próximo al acantilado oriental del Cerro de San Juan. turdetana y romana, es decir, de cuando el sitio se conoció con el nombre de Caura, topónimo de raíz indoeuropea (Padilla, 1993).

El asentamiento ocupa la orilla occidental del paleoestuario del Guadalquivir. Algunos estudios geoarqueológicos conocen este sector como "Estrecho de Coria” (Arteaga et al., 1995: 109), una zona que en la margen izquierda del río contaba con otro hábitat calcolítico bajo la antigua ciudad de Orippo

(Fernández Gómez et al., 1997: 137-138). Desde aquí se podía acceder fácilmente hasta Valencina, asentamiento con la mayor población de la comarca durante la Edad del Cobre. Se hacía Guadalquivir arriba por vía fluvial o por la cañada del río Pudio usando caminos terrestres. Estas conexiones locales han sido corroboradas recientemente con el análisis de los monolitos 
de arenisca empleados en la techumbre de la Cueva de la Pastora, que se extrajeron de los alrededores de Coria del Río (Cáceres et al., 2014: 443-445).

\subsection{Secuencia estratigráfica}

Las excavaciones en el cabezo se han llevado a cabo básicamente en dos sectores: el del flanco que da al Guadalquivir y el del centro de la meseta. En el primero se practicó un sondeo estratigráfico como actuación del Proyecto Estuario (Escacena e Izquierdo, 1999). El segundo corresponde a una intervención de urgencia que no encontró niveles prehistóricos a pesar de haber alcanzado también el sustrato geológico (Escacena e Izquierdo, 2001). Esto indica que el hábitat calcolítico y del Bronce antiguo se limitó al parecer al borde del cabezo desde el que se controlaba el río. Por tanto, la documentación del Cerro de San Juan sobre la que basamos el presente artículo procede exclusivamente del llamado Sondeo A, excavado durante 1994 y 1996 en sendas campańas. Esta cata perseguía obtener la mayor secuencia estratigráfica posible del asentamiento. Por eso se eligió el flanco más cercano al Guadalquivir, donde la hipótesis inicial preveía el nacimiento del hábitat al considerar el propio cauce fluvial uno de los factores principales de atracción, sobre todo por los recursos económicos que ofrecía y por su facilidad para emplearlo como vía de comunicaciones (Fig. 3).

La intervención consistió en la apertura de un corte rectangular, de $10 \times 6 \mathrm{~m}$, acomodado al espacio vacío que dejó junto al flanco oriental del cerro uno de los edificios hoy existentes, el IEs Caura. La extensión inicial se redujo con la profundidad, tanto por razones presupuestarias como por no desmontar las estructuras antiguas localizadas, correspondientes a tiempos protohistóricos y romanos básicamente. La excavación se llevó a cabo mediante el levantamiento de estratos -E-, respetando siempre los límites sedimentarios de éstos y su conformación. Aun así, algunos de estos paquetes se subdividieron en niveles artificiales $-\mathrm{N}-$, sobre todo para poder detectar una posible evolución de su contenido arqueológico sin correspondencia en la sedimentación.

La secuencia estratigráfica se inicia con dos estratos -E-I y E-II- que representan la base documental de este trabajo (Fig. 4). El inferior -E-I- se superpone directamente al suelo original del cabezo, que está constituido por arcillas rojas muy compactas e impermeables con presencia de cantos rodados de cuarcita. Este sustrato geológico corresponde a parte de una terraza del Guadalquivir que se extiende por el flanco sur del Aljarafe, y que incluye a veces guijarros tallados paleolíticos. En el sector excavado no se detectaron estructuras constructivas en este paquete E-I, aunque sí mucha actividad antrópica. Esta última se deduce de la abundancia de fragmentos de cerámica y de la presencia de elementos líticos, entre ellos algunos dientes de hoz. Igualmente, son numerosos los restos óseos de animales domésticos y la fauna de estuario, todos ellos interpretables en principio como restos de la alimentación humana. E-I está formado por tierras arcillosas compactas de color pardo y acastańado, que se van enrojeciendo con la profundidad y ennegreciendo con la altura. El material arqueológico, típico de la fase final del Calcolítico meridional hispano, cuenta con abundante cerámica campaniforme. Pero están ausentes los grandes platos de borde engrosado, tan bien caracterizados en la cercana Valencina (Ruiz Mata, 1975a). Este estrato inicial es producto de una decantación lenta de sedimentos. Durante su levantamiento arqueológico nunca se detectaron rasgos típicos de una acumulación rápida de detritos, como podría ser la posición vertical de algunos fragmentos cerámicos de gran tamaño o de huesos largos de animales. Esta lentitud del proceso de sedimentación es uno de los factores que sin duda explica su alta compacidad, a lo que hay que unir el peso de la acumulación estratigráfica posterior.

El estrato que se superpone a esta ocupación inicial está compuesto también por una matriz principalmente arcillosa, ahora prácticamente de color negro casi uniforme o castańo muy oscuro -E-II-. Apenas cuenta con cerámica campaniforme, lo que evidencia un cambio cultural significativo. Este otro estrato contenía un hogar en el que se usaron como soporte para las vasijas tres piedras de mediano tamaño. Dos de ellas eran bloques irregulares de arenisca y la tercera un fragmento de molino de mano de granito. El granito aflora en los alrededores de Gerena, unos $30 \mathrm{~km}$ al N, mientras que la arenisca compone parte del sustrato geológico del propio Cerro de San Juan y de otros cercanos. Este hogar puede considerarse la única estructura localizada en E-II. Por lo demás, el estrato contenía abundante cerámica, aunque menos fracturada que 
la de E-I; también varias piezas líticas, entre ellas nuevamente dientes de hoz. Su tierra oscura evidencia su alto contenido orgánico, que se manifiesta en diversas películas de carboncillos y en los abundantes restos de fauna. La matriz arcillosa del mismo revela su composición a base de limos y arcillas de pequeña granulometría, y obedece en parte a que también este estrato es de formación lenta, como el anterior, seguramente decantado paulatina y homogéneamente a lo largo de todo el tiempo que habitó allí la comunidad humana que lo produjo. El hogar referido está situado casi en el límite superior del estrato y contenía los fragmentos de vasijas de mayor tamaño localizados en este contexto. Tal circunstancia podría re-

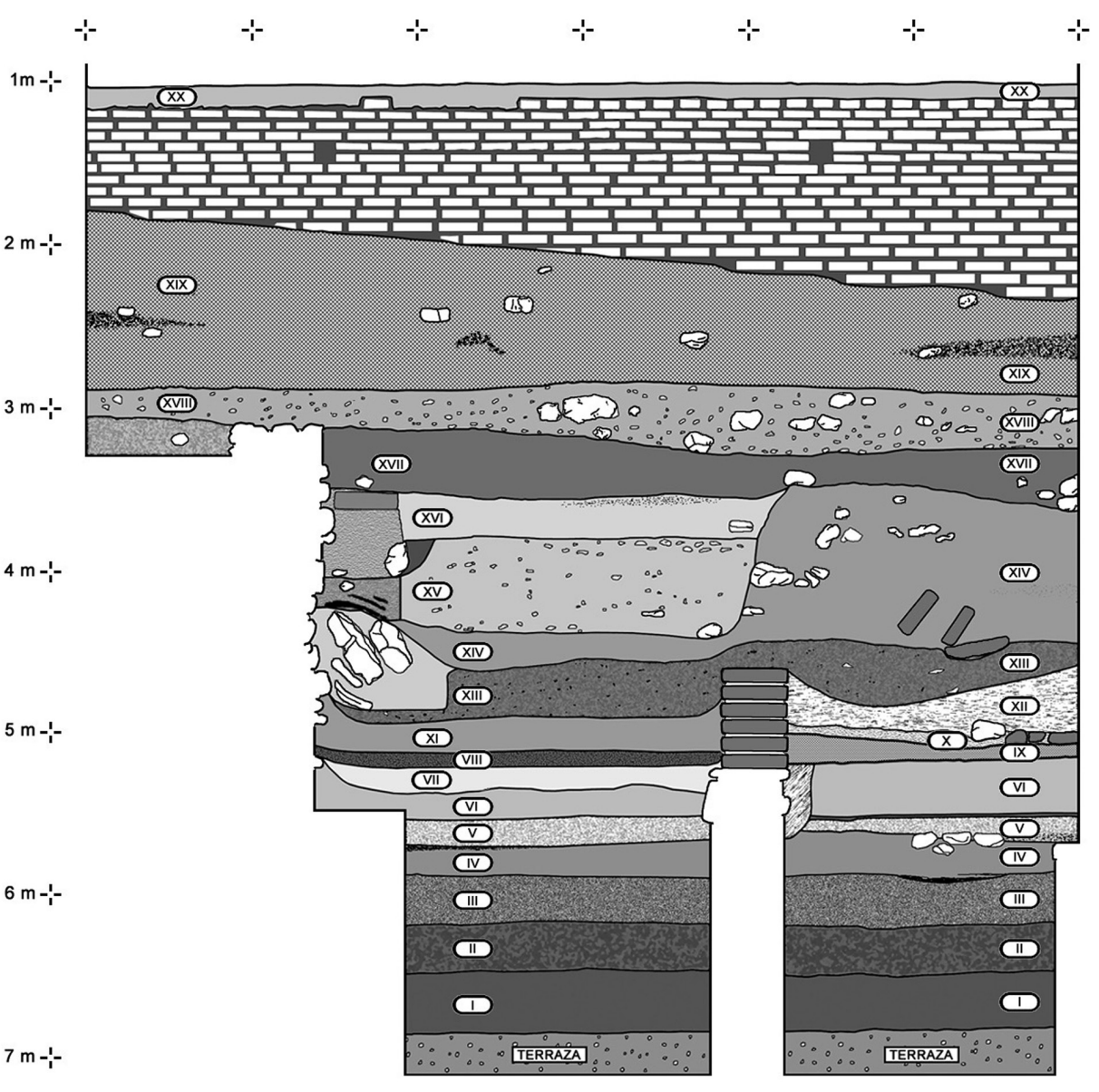

FIG. 4. Dibujo del perfil estratigráfico obtenido en el Corte A del Cerro de San Juan. velar que este sector del yacimiento -si no todo él-se abandonó durante un tiempo en coincidencia con el final de la ocupación del Bronce antiguo. De hecho, por encima de E-II, y en contacto directo con su techo, se detectaron contextos de época tartésica, lo que conllevaría una posible ausencia de poblamiento en el Cerro de San Juan durante el Bronce medio.

Estos dos estratos primeros de la secuencia disponen de una potencia sedimentaria similar, entre 45 $\mathrm{cm}-\mathrm{E}-\mathrm{I}-$ y $40 \mathrm{~cm}-\mathrm{E}-\mathrm{II}-$. Y, como fueron excavados en igual extensión, podemos aceptar que contenían valores volumétricos muy parecidos. Dicho rasgo, unido al hecho de que en ninguno de los dos se hallaron restos de construcciones, permite realizar fáciles correlaciones estadísticas con sus materiales.

En el estrato de base -E-I-, correspondiente a la Edad del Cobre, se diferenciaron durante la excavación de 1994 cinco niveles artificiales, que recibieron

las siguientes identificaciones: CAU-94-63, CAU-9464, CAU-94-65, CAU-94-66 y CAU-94-67. Al comprobar que todas esas subdivisiones respondían en realidad a un mismo paquete sedimentario, durante la ampliación del sondeo en 1996 todo lo excavado en esta unidad recibió una sola clave: CAU-96-87. En el estrato del Bronce antiguo -E-II- se aislaron durante 1994 tres niveles: CAU-94-60, CAU-94-61 y CAU-9462. Durante la campaña de 1996, la precaución de establecer niveles artificiales permitió aislar en este estrato una pequeńa bolsa que, sin presentar de visu sedimentos diferentes del resto del estrato, contenía en cambio una ligera contaminación de materiales, pues aparecieron algunos fragmentos de cerámica de época tartésica en su parte superior. Así, en E-II se distinguieron dos niveles en la ampliación de 1996: CAU-96-84 y CAU-96-86. La Fig. 5 muestra un resumen de estas equivalencias. 


\begin{tabular}{|c|c|c|c|c|}
\hline \multicolumn{2}{|c|}{ NIVELES ARTIFICIALES (N) } & \multicolumn{2}{|c|}{ ESTRATOS (E) } & \multirow{2}{*}{$\begin{array}{l}\text { ASIGNACIÓN } \\
\text { CULTURAL }\end{array}$} \\
\hline 1994 & 1996 & 1994 & 1996 & \\
\hline $\begin{array}{l}N-56 \\
N-57 \\
N-58 \\
N-59\end{array}$ & $\begin{array}{l}\mathrm{N}-80 \\
\mathrm{~N}-82 \\
\mathrm{~N}-83\end{array}$ & E-III & E-III & MUNDO TARTÉSICO \\
\hline $\begin{array}{l}N-60 \\
N-62 \\
N-6 I \\
\end{array}$ & $\begin{array}{l}N-84 \\
N-86\end{array}$ & E-II & E-II & BRONCE ANTIGUO \\
\hline $\begin{array}{l}N-63 \\
N-64 \\
N-65 \\
N-66 \\
N-67\end{array}$ & $\mathrm{~N}-87$ & E-I & E-I & $\begin{array}{l}\text { CALCOLÍTICO FINAL } \\
\text { (CAMPANIFORME) }\end{array}$ \\
\hline
\end{tabular}

FIG. 5. Sintesis interpretativa de la secuencia ocupacional en el Sondeo a del Cerro de San Juan (Coria del Río, Sevilla); se recogen exclusivamente los contextos estratigráficos prehistóricos y el más antiguo de época tartésica. ya que no existen en el conjunto otros elementos cerámicos típicos y exclusivos de este periodo -como por ejemplo platos de bordes engrosados-. Para la fase del Bronce antiguo se han considerado fósiles guía las formas tradicionalmente denominadas con los siguientes términos: cuencos de borde entrante, cuencos carenados con cuellos convexos -forma de hipérbole-, botellas y tulipas (Fig. 7).

La variable forma se ha sintetizado en una serie de tipos que constituye un equilibrio eficiente entre la natural diversidad continua de todo conjunto arqueológico y el establecimiento

Las siglas utilizadas responden a la abreviatura del nombre antiguo de la ciudad $-\mathrm{CAU}=$ Caura - , seguida de los dos últimos dígitos del año de la intervención -94 = 1994; 96 = 1996- y del número del nivel artificial. Con ellas se han marcado también los materiales arqueológicos, en este caso añadiéndoles al final el número de cada pieza, en series del 1 al infinito por cada nivel. Todos los elementos procedentes del Sondeo A se encuentran depositados en el Museo Arqueológico de Sevilla.

\subsection{Materiales cerámicos y métodos}

A continuación se realizan diferentes aproximaciones sistemáticas estadísticas con base en diversas combinaciones de las siguientes variables: tipos cerámicos considerables fósiles guía históricos, forma, decoración y estratos.

En cuanto a los tipos cerámicos que pueden catalogarse como fósiles guía, se pretende una aproximación que considere las variedades arqueológicas tradicionalmente asociadas al Calcolítico campaniforme y al Bronce antiguo, y ver cómo se comporta el análisis del caso del Cerro de San Juan de Coria del Río según esta visión tradicional. Se han identificado como tales sólo los registros cerámicos que pueden adscribirse con garantía a uno de los dos periodos. Para el Calcolítico se han tenido en cuenta sólo los registros campaniformes (Fig. 6), de un sistema taxonómico que simplifique y represente aquélla de forma sencilla y operativa. La tipología preestablecida en esta aproximación cuenta con las siguientes categorías: botella, cazuela, cuenco, cuenco carenado, cuenco de borde entrante, globular, tulipa y vaso.

La variable decoración cuenta con las siguientes categorías: impreso-inciso, inciso, liso, marítimo, pintado y puntillado geométrico. La diversidad decorativa campaniforme, que en gran parte vertebra esta variable, ha seguido el esquema taxonómico más usado actualmente en la bibliografía especializada (García Rivero, 2007, 2008, 2009; Lazarich, 1999, 2005a; Valera, 2006).

Dado que este estudio pone un énfasis especial en la comparación y determinación de la similitud y diferencia entre los conjuntos cerámicos de dos estratos datados respectivamente en la Edad del Cobre y en la del Bronce, se realizan aproximaciones que de algún modo analicen si hay diferencia significativa entre ambos conjuntos.

Se realizan análisis de correspondencias, una técnica de ordenación descriptiva multivariante que se sustenta en tablas de contingencia donde los datos se escalan de forma equivalente; es decir, con el mismo peso en las distribuciones para filas y columnas.

Al margen de los análisis estadísticos descriptivos, se realizan también pruebas de contraste de hipótesis mediante estadística inferencial. Concretamente 


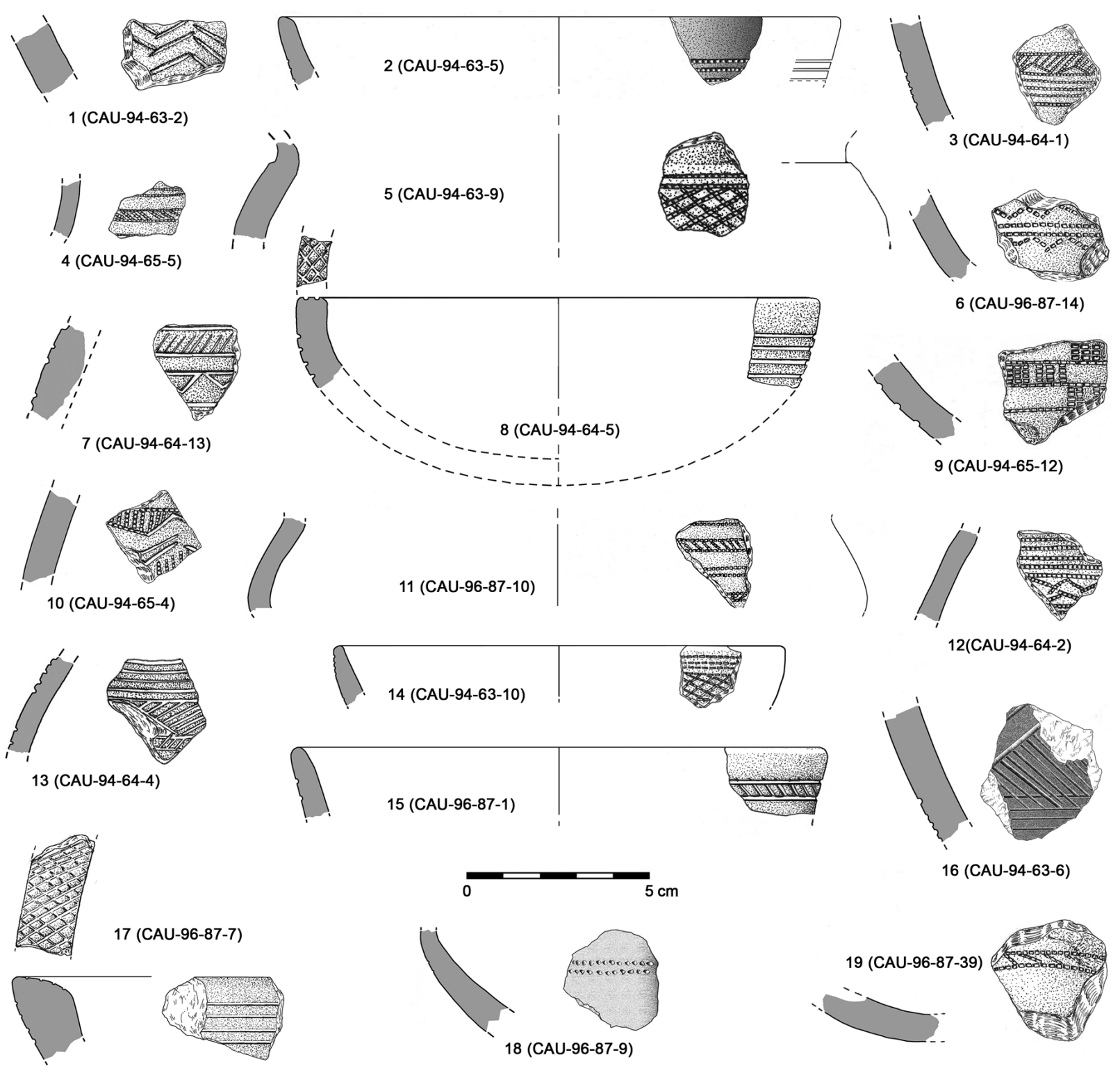

FIG. 6. Cerámicas campaniformes documentadas en el Estrato I del Corte A del Cerro de San Juan.

se utiliza la prueba $\chi^{2}$-Chi Cuadrado de Pearson-. Se trata de una operación no paramétrica -dada la escala nominal de nuestras variables- que mide la discrepancia entre una distribución observada y otra teórica, indicando el grado en que las diferencias existentes entre ambas se deben al azar en el contraste de hipótesis. En nuestro caso específico, se utiliza para probar la independencia de dos variables entre sí, mediante la presentación de los datos en tablas de contingencia y la obtención del valor $p$, el cual nos indicará la significación estadística para el contraste de las hipótesis. Concretamente se realizarán dos pruebas Chi Cuadrado para determinar la independencia entre las variables forma y decoración -los datos cerámicos de los que disponemos-, respecto a la ubicación de las cerámicas en ambos estratos. 


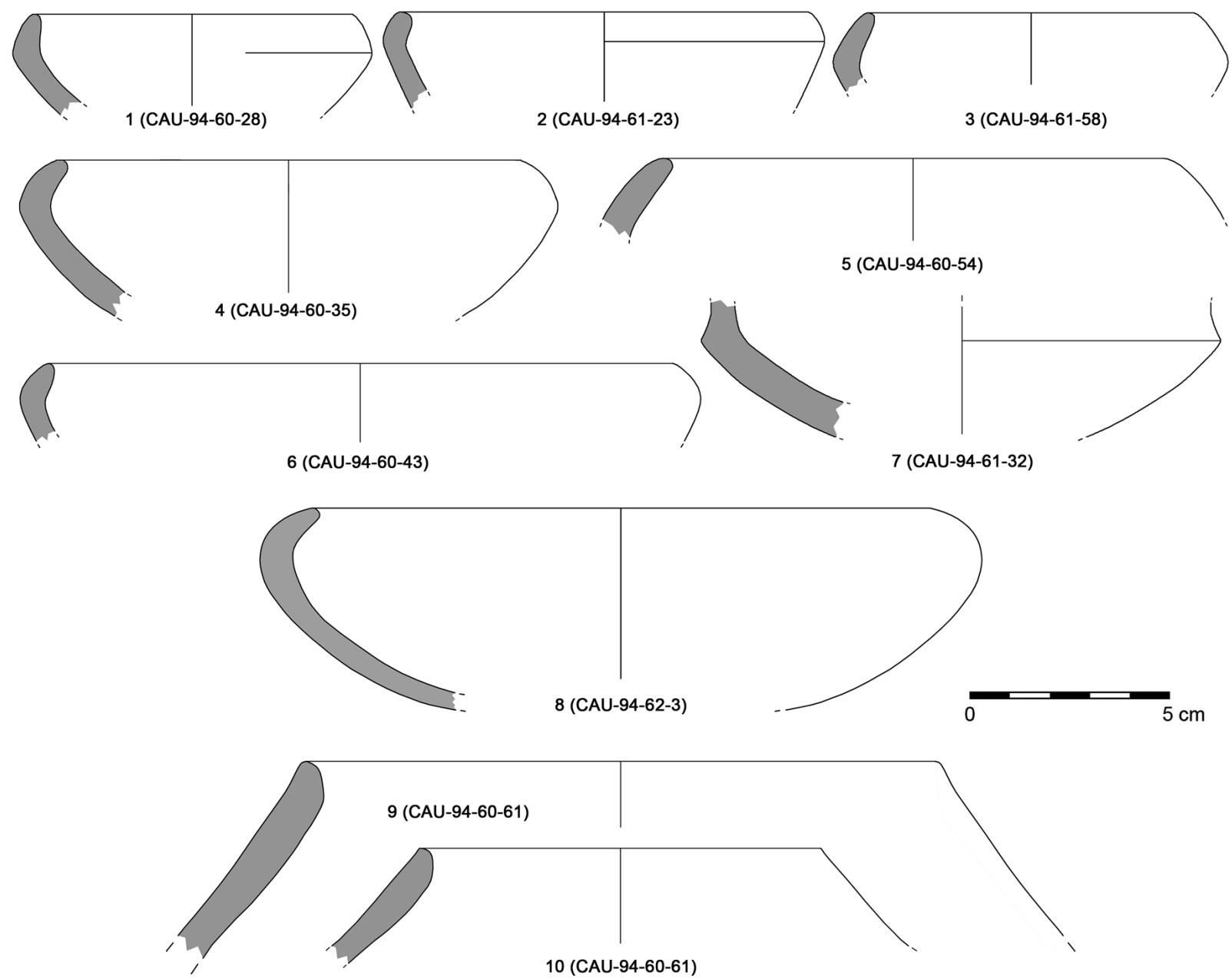

Fig. 7. Cerámicas del Bronce antiguo documentadas en el Estrato II del Corte A del Cerro de San Juan.

\section{Resultados}

\subsection{Cuantificación y análisis estadísticos}

En la fase prehistórica del Cerro de San Juan de Coria del Río se documentan, siempre dentro del denominado Sondeo A, 3325 registros cerámicos, que se reparten de forma relativamente equitativa entre las dos unidades estratigráficas que se consideran en este trabajo: 1500 de ellos en E-I y 1825 en E-II (Fig. 8).

Según las categorías establecidas, sólo 185 de los 3325 registros pueden adscribirse al Calcolítico campaniforme -63 casos- o al Bronce antiguo -122(Fig. 9).
Como puede observarse en la Fig. 10, E-I cuenta con 58 registros de época campaniforme y 12 del Bronce antiguo. Esto supone unos porcentajes del $92,1 \%$ y del $7,9 \%$ respectivamente. E-II contiene 5 registros de época campaniforme y 110 del Bronce antiguo, lo que representa unos valores del 9,8\% y del $90,2 \%$ en cada caso.

Si se atiende a la variable forma, se pueden adscribir tipológicamente 235 registros, que constituyen un $7,1 \%$ del conjunto total cerámico. En términos generales (Fig. 11), el orden de las formas, representadas de mayor a menor presencia, es el siguiente: cuenco de borde entrante, cuenco, recipiente globular, vaso, botella, cuenco carenado, cazuela y tulipa. La 
Fig. 12 compara las frecuencias y porcentajes relativos de cada categoría formal según su ubicación estratigráfica. Las diferencias más notables las constituyen los siguientes tipos: cazuela -presente sólo en E-I- y botella -con un $92,3 \%$ en E-II-. Les siguen los vasos - con un $77,8 \%$ en E-I- y los cuencos carenados con un $83,3 \%$ en E-II-.

Respecto a la variable decoración, en términos generales, el $98,1 \%$ del conjunto es liso, siguiendo ordinalmente las categorías inciso, marítimo, puntillado geométrico, pintado e impreso-inciso. La Fig. 13 muestra las frecuencias y porcentajes de cada categoría decorativa según su procedencia estratigráfica. Las diferencias más notables vienen dadas por las decoraciones calificables como puntillado geométrico e impreso-inciso -ambas presentes exclusivamente en E-I-, seguidas por marítimo e inciso - con un $95,2 \%$ y un $88 \%$, respectivamente, en E-I-.

La Fig. 14 muestra las correspondencias entre todas las categorías de las variables forma y decoración. Del análisis elaborado en el software Canoco 4.5 con base en las variables forma y decoración, se obtiene el resultado gráfico expuesto en la Fig. 15. A lo largo del eje vertical de la distribución se puede observar claramente la existencia de dos grupos diferentes que se correlacionan con los dos periodos cronoculturales considerados.

La Fig. 16 procede de un análisis de correspondencias realizado en el software Spss v. 22.0 con base en las variables forma y decoración. En este caso, el resultado expone la distribución de las diferentes categorías de nuestras variables en vez de la dispersión de

los registros cerámicos. Como puede observarse, las relaciones más estrechas entre las categorías tenidas en cuenta vienen dadas por la cazuela con puntillado geométrico, el vaso con marítimo y, un poco menos estrecha, el vaso con inciso, y, por último, el resto de tipos morfológicos con ausencia de decoración.

Del análisis de correspondencias elaborado en el software Canoco 4.5 con base en las variables forma y decoración según la pertenencia a uno u otro estrato -A: E-I; B: E-II-, se obtiene el gráfico de la Fig. 17. A lo largo de la distribución se puede observar la existencia de dos concentraciones fundamentales que suponen la mayoría de registros y que se corresponden respectivamente con las cerámicas de E-I y E-II.

\begin{tabular}{|c|c|c|c|c|c|}
\hline & & & \multicolumn{2}{|c|}{ Estratos } & \multirow[b]{2}{*}{ Total } \\
\hline & & & Estrato I & Estrato II & \\
\hline \multirow[t]{6}{*}{ Cerámicas fósiles guía culturales } & \multirow[t]{2}{*}{ Indeterminado } & Recuento & 1430 & 1710 & 3140 \\
\hline & & Porcentajes & $45,5 \%$ & $54,5 \%$ & \\
\hline & \multirow[t]{2}{*}{ Campaniforme } & Recuento & 58 & 5 & 63 \\
\hline & & Porcentajes & $92,1 \%$ & $7,9 \%$ & \\
\hline & \multirow[t]{2}{*}{ Bronce antiguo } & Recuento & 12 & 110 & 122 \\
\hline & & Porcentajes & $9,8 \%$ & $90,2 \%$ & \\
\hline \multirow[t]{2}{*}{ Total } & & Recuento & 1500 & 1825 & 3325 \\
\hline & & Porcentajes & $45,1 \%$ & $54,9 \%$ & \\
\hline
\end{tabular}

FIG. 10. Frecuencias y porcentajes de cerámicas fósiles guia según estratos. 


\begin{tabular}{|c|c|c|c|c|}
\hline & & FRECUENCIA & Porcentaje & $\begin{array}{l}\text { PORCENTAJE } \\
\text { ACUMULADO }\end{array}$ \\
\hline \multirow[t]{10}{*}{ Válido } & Indeterminado & 3090 & 92,9 & 92,9 \\
\hline & Cuenco borde entrante & 91 & 2,7 & 95,7 \\
\hline & Cuenco & 77 & 2,3 & 98,0 \\
\hline & Globular & 23 & ,7 & 98,7 \\
\hline & Vaso & 18 &, 5 & 99,2 \\
\hline & Botella & 13 & 4 & 99,6 \\
\hline & Cuenco carenado & 6 & ,2 & 99,8 \\
\hline & Cazuela & 4 & 1 & 99,9 \\
\hline & Tulipa & 3 & 1 & 100,0 \\
\hline & TOtal & 3325 & 100,0 & \\
\hline
\end{tabular}

Spss v. 22. Recuérdese que este análisis prueba la independencia entre la variable forma y los estratos. Es decir, nos dice si la variable forma depende de la variable estrato -la ubicación de las cerámicas en uno u otro estrato-; y que la hipótesis nula $-\mathrm{H} 0$ - es que no hay dependencia entre estrato y la variable forma. El valor $p$ resultante es 0,00 , es decir, que hay evidencia al $100 \%$ para rechazar que la variable forma no se supedite a la variable estrato. $\mathrm{O}$, lo que es lo mismo,

FIG. 11. Frecuencias y porcentajes de las distintas formas.

La Fig. 18 muestra la contingencia para las categorías de la variable forma en relación con los estratos, mientras que la Fig. 19 expone los resultados del análisis de Chi Cuadrado de Pearson elaborado en

\begin{tabular}{|c|c|c|c|c|c|}
\hline & & & EsTR & & \\
\hline & & & Estrato I & Estrato II & TOTAL \\
\hline FORMA & Indeterminado & Recuento & 1418 & 1672 & 3090 \\
\hline & & Porcentaje & $45,9 \%$ & $54,1 \%$ & \\
\hline & Vaso & Recuento & 14 & 4 & 18 \\
\hline & & Porcentaje & $77,8 \%$ & $22,2 \%$ & \\
\hline & Cuenco & Recuento & 30 & 47 & 77 \\
\hline & & Porcentaje & $39,0 \%$ & $61,0 \%$ & \\
\hline & Cuenco borde entrante & Recuento & 25 & 66 & 91 \\
\hline & & Porcentaje & $27,5 \%$ & $72,5 \%$ & \\
\hline & Cuenco carenado & Recuento & 1 & 5 & 6 \\
\hline & & Porcentaje & $16,7 \%$ & $83,3 \%$ & \\
\hline & Cazuela & Recuento & 4 & 0 & 4 \\
\hline & & Porcentaje & $100,0 \%$ & $0,0 \%$ & \\
\hline & Globular & Recuento & 6 & 17 & 23 \\
\hline & & Porcentaje & $26,1 \%$ & $73,9 \%$ & \\
\hline & Botella & Recuento & 1 & 12 & 13 \\
\hline & & Porcentaje & $7,7 \%$ & $92,3 \%$ & \\
\hline & Tulipa & Recuento & 1 & 2 & 3 \\
\hline & & Porcentaje & $33,3 \%$ & $66,7 \%$ & \\
\hline Total & & Recuento & 1500 & 1825 & 3325 \\
\hline & & Porcentaje & $45,1 \%$ & $54,9 \%$ & \\
\hline
\end{tabular}

FIG. 12. Frecuencias y porcentajes de las distintas formas según estratos. que la variable forma depende de la variable estrato, es decir, que los valores que toman las distintas formas de las cerámicas de nuestro conjunto total se deben a la posición estratigráfica. Por tanto, son distintas con significación estadística entre ambos paquetes sedimentarios.

La Fig. 20 recoge la contingencia para las categorías de la variable decoración en relación con los estratos, mientras que la Fig. 21 expone los resultados del análisis de Chi Cuadrado de Pearson. En este caso, se prueba la independencia entre la variable decoración y los estratos. La hipótesis nula $-\mathrm{H} 0$ - es que no hay dependencia entre estrato $y$ la variable decoración. El valor $p$ resultante es 0,00 , es decir, que hay evidencia al 100\% para rechazar que la variable decoración sea independiente de la variable estrato. $\mathrm{O}$, lo que es lo mismo, que la variable decoración depende de la variable estrato, es decir, que los valores que toman las distintas decoraciones de las cerámicas de nuestro conjunto total dependen de los estratos. Por tanto, son distintas con significación estadística entre E-I y E-II. 


\subsection{Dataciones radiocarbónicas}

Las Figs. 22 y 23 muestran los resultados del conjunto de análisis radiocarbónicos efectuados. Hay disponibles 10 fechas, 7 para el E-I y 3 para el E-II.

La muestra de fechas de E-I abarca un intervalo cronológico máximo de 2146-1751 cal AC, mientras que la del E- II supone la horquilla $1976-1734$ cal AC. Si se extraen las medias de los intervalos de probabilidad, el intervalo de E-I sería 2125$1836 \mathrm{cal} \mathrm{AC,}$ mientras que el de E- II sería 1871-1815 cal AC.

Puede observarse que el intervalo cronológico de ambos estratos no es muy amplio, particularmente para E- II, cuyas

\begin{tabular}{|c|c|c|c|c|c|}
\hline & \multicolumn{2}{|c|}{ Estrato } & \multirow[b]{2}{*}{ TотAL } \\
\hline & & & Estrato I & Estrato II & \\
\hline \multirow[t]{12}{*}{ DeCORACión } & \multirow[t]{2}{*}{ Liso } & Recuento & 1442 & 1819 & 3261 \\
\hline & & Porcentaje & $44,2 \%$ & $55,8 \%$ & \\
\hline & \multirow[t]{2}{*}{ Marítimo } & Recuento & 20 & 1 & 21 \\
\hline & & Porcentaje & $95,2 \%$ & $4,8 \%$ & \\
\hline & \multirow[t]{2}{*}{ Puntillado Geométrico } & Recuento & 13 & 0 & 13 \\
\hline & & Porcentaje & $100,0 \%$ & $0,0 \%$ & \\
\hline & \multirow[t]{2}{*}{ Impreso-Inciso } & Recuento & 2 & 0 & 2 \\
\hline & & Porcentaje & $100,0 \%$ & $0,0 \%$ & \\
\hline & \multirow[t]{2}{*}{ Inciso } & Recuento & 22 & 3 & 25 \\
\hline & & Porcentaje & $88,0 \%$ & $12,0 \%$ & \\
\hline & \multirow[t]{2}{*}{ Pintado } & Recuento & 1 & 2 & 3 \\
\hline & & Porcentaje & $33,3 \%$ & $66,7 \%$ & \\
\hline \multirow{2}{*}{\multicolumn{2}{|c|}{ TотAL }} & Recuento & 1500 & 1825 & 3325 \\
\hline & & Porcentaje & $45,1 \%$ & $54,9 \%$ & \\
\hline
\end{tabular}

Fig. 13. Frecuencias y porcentajes de las distintas decoraciones según estratos. fechas se concentran en el s. XIX cal AC. Al margen de esta observación, el punto más interesante radica en las fechas relativamente tardías de E- I, de la Edad del Cobre, si bien el momento de transición entre ambos periodos cronoculturales se sitúa dentro del panorama común en el occidente andaluz ( $c f$. Mederos, 1996; Hunt et al., 2008; García Sanjuán y Hurtado, 2011). Más adelante se trata el panorama general de esta transición a nivel regional según las dataciones radiocarbónicas disponibles, pero ahora es interesante anotar que en algunas zonas cabe la posibilidad de un solapamiento cronológico

entre las manifestaciones materiales de ambos periodos arqueológicos. Por tanto, si bien los análisis estadísticos previamente efectuados indican que ambos conjuntos arqueológicos son distintos, del panorama cronológico se infiere que ambos no tienen por qué ser distantes.

\section{Discusión}

En el Cerro de San Juan de Coria del Río se ha documentado cerámica campaniforme en muy di-

\begin{tabular}{|l|c|c|c|c|c|c|}
\hline \multirow{2}{*}{ Forma } & \multicolumn{7}{|c|}{ DeCoración } \\
\cline { 2 - 7 } & Liso & Marítimo & $\begin{array}{c}\text { Puntillado } \\
\text { Geométrico }\end{array}$ & $\begin{array}{c}\text { Impreso- } \\
\text { Inciso }\end{array}$ & Inciso & Pintado \\
\hline Vaso & 1 & 10 & 2 & 0 & 5 & 0 \\
\hline Cuenco & 75 & 0 & 0 & 0 & 2 & 0 \\
\hline Cuenco borde entrante & 91 & 0 & 0 & 0 & 0 & 0 \\
\hline Cuenco carenado & 6 & 0 & 0 & 0 & 0 & 0 \\
\hline Cazuela & 1 & 0 & 2 & 0 & 1 & 0 \\
\hline Globular & 23 & 0 & 0 & 0 & 0 & 0 \\
\hline Botella & 13 & 0 & 0 & 0 & 0 & 0 \\
\hline Tulipa & 3 & 0 & 0 & 0 & 0 & 0 \\
\hline
\end{tabular}
versos ambientes estratigráficos, que van desde los calcolíticos hasta los que se originaron en obras realizadas en el cabezo durante el pasado s. xx. Pero, como hemos visto, todos los fragmentos aparecidos fuera de E- I pueden considerarse elementos residuales según la terminología de Harris (1991: 166). Este enclave constituye uno de los pocos sitios de Andalucía occidental donde existe una superposición clara de un contexto del Bronce an-

FIG. 14. Tabla de correspondencias entre las variables forma y decoración. tiguo -E-II- sobre otro anterior 


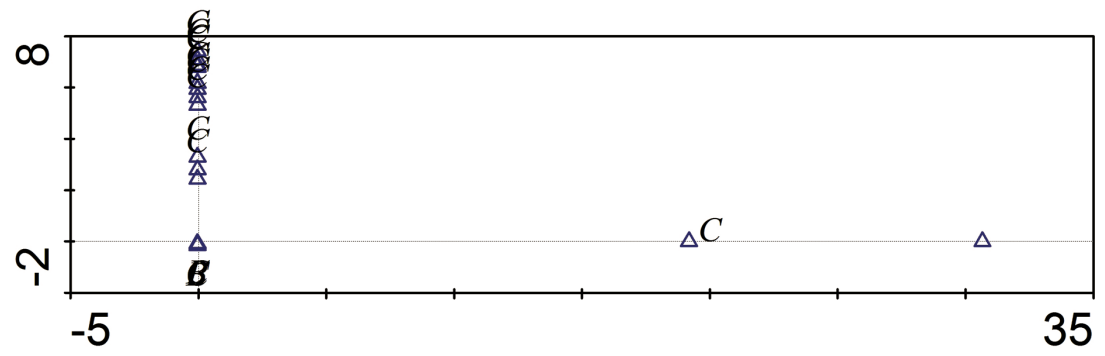

Fig. 15. Gráfico de distribución de análisis de correspondencias [Canoco 4.5] con base en las variables forma (obviando los registros con formas indeterminadas) y decoración según la adscripción cronológica cultural a fósiles guia (C: Calcolítico; B: Bronce).

correspondiente al mundo campaniforme -E-I-. Sin embargo, la secuencia sedimentaria del Cerro de San Juan no demuestra en principio, y por sí misma, ni la continuidad poblacional de un mismo grupo humano ni la sustitución de poblaciones entre ambas fases. Defender la pervivencia démica conllevaría aceptar

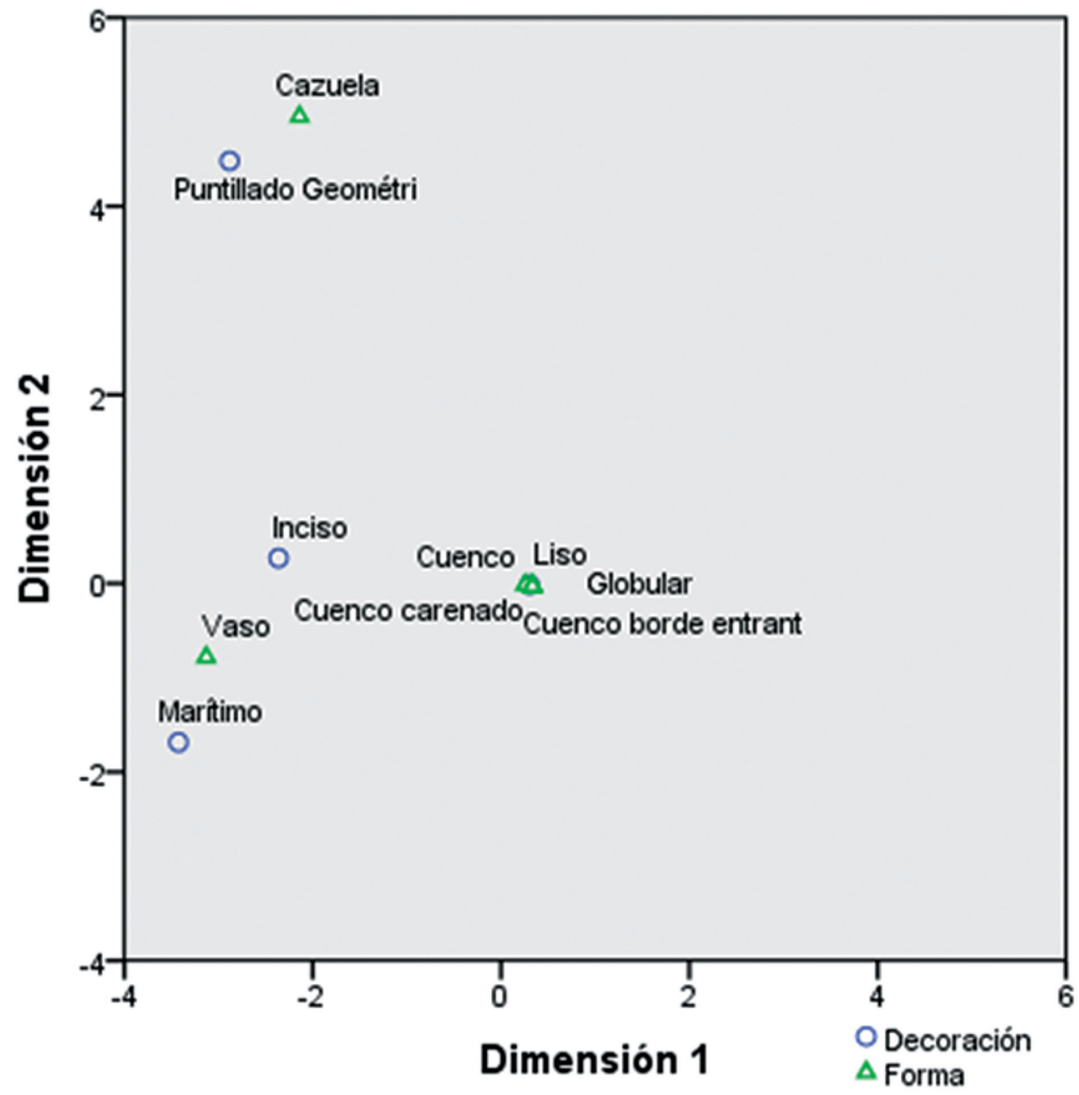

FIG. 16. Gráfico de distribución de las diferentes categorías de las variables forma (obviando los registros con formas indeterminadas) y decoración procedente de análisis de correspondencias [SPSS 22.0]. una aceleración del cambio cultural, ya que lo constatado en el material arqueológico revela que estamos, entre otras transformaciones, ante un complejo alfarero muy distinto del anterior. Por el contrario, la hipótesis de un reemplazo de la población humana obligaría a sostener que fue la especial ubicación del promontorio la causa que atrajo a una gente nueva, originando la lógica superposición de sedimentos sobre el lugar. Si esta segunda explicación fuera la adecuada a los datos locales y regionales, sería necesario analizar algún día -cosa que no es objeto del presente artículo- cómo y por qué se produjo dicha sustitución demográfica. Sí parece estar claro que las diferencias sedimentarias entre los E-I y E-II, sin ser radicales, obedecen a condiciones de formación distintas. En ambos estratos faltan derrumbes de edificios y aportes intencionados de tierras. Sin embargo, sus diferencias edáficas justifican suficientemente haberlos individualizado durante los trabajos de campo. En consecuencia, puede ser una buena explicación de sus rasgos particulares el hecho de que se originaron a partir de unos modos de vida disímiles. Es posible que algunas de las claves que permitan inclinar la balanza hacia una u otra hipótesis se encuentren en otros sitios de Andalucía occidental. Por ello, nos referiremos ahora a los principales yacimientos de la zona que cuentan con una ocupación del Bronce antiguo precedida de otra de finales de la Edad del Cobre.

Entre los emplazamientos más cercanos a Coria del Río que cuentan con superposición de estratos del Cobre y del Bronce se puede citar Valencina de la Concepción, uno de los 
centros más grandes del bajo valle bético durante el Calcolítico. Sin embargo, a pesar de que se han identificado aquí elementos arqueológicos asignados genéricamente a la Edad del Bronce (Ruiz Mata, 1975b), apenas se conocen superposiciones estratigráficas directas de niveles de esta fase sobre los calcolíticos anteriores. Téngase en cuenta además que cuando se publicó este trabajo de Ruiz Mata al Calcolítico se le denominaba entonces Bronce I Hispano. Casi todo el asentamiento de Valencina se caracteriza por lo que ha venido a denominarse una "estratigrafía

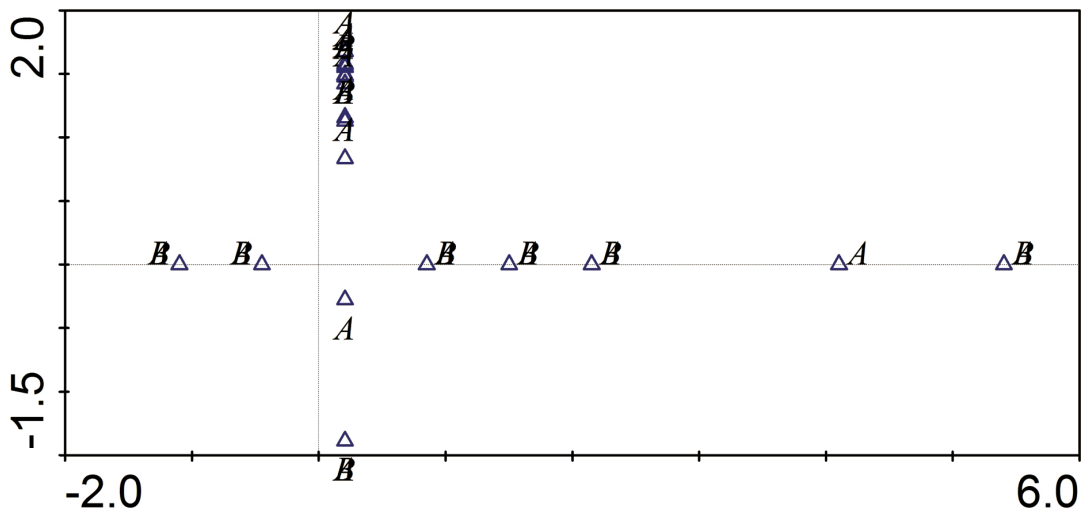

FIG. 17. Gráfico de distribución de análisis de correspondencias [Canoco 4.5] con base en las variables forma (obviando los registros con formas indeterminadas) y decoración (obviando los registros sin decoración) según la pertenencia a uno u otro estrato (A: Estrato I; B: Estrato II).

\begin{tabular}{|c|c|c|c|c|c|c|c|c|c|}
\hline \multicolumn{10}{|c|}{ FORMA } \\
\hline Estrato & 1 & 2 & 3 & 4 & 5 & 6 & 7 & 8 & Total \\
\hline \multirow[t]{2}{*}{1} & 14,00 & 30,00 & 25,00 & 1,00 & 4,00 & 6,00 & 1,00 & 1,00 & 82,00 \\
\hline & 6,28 & 26,87 & 31,75 & 2,09 & 1,40 & 8,03 & 4,54 & 1,05 &, 00 \\
\hline \multirow[t]{2}{*}{2} & 4,00 & 47,00 & 66,00 & 5,00 & , 00 & 17,00 & 12,00 & 2,00 & 153,00 \\
\hline & 11,72 & 50,13 & 59,25 & 3,91 & 2,60 & 14,97 & 8,46 & 1,95 & ,00 \\
\hline TOTAL & 18,00 & 77,00 & 91,00 & 6,00 & 4,00 & 23,00 & 13,00 & 3,00 & 235,00 \\
\hline
\end{tabular}

FIG. 18. Tabla de contingencia para las variables forma y estrato. Se han suprimido los casos con forma indeterminada. Para cada combinación posible entre las categorías de forma y estratos aparecen dos valores: el superior es el recuento y el inferior es el valor esperado. Por ejemplo, para la forma 1 en el Estrato I se contabilizan 14 casos, mientras que el valor teórico esperado es 6,28.

horizontal". Existen dos dataciones (Fig. 24) que se sitúan a caballo entre el III y II milenios cal BC, pero la información publicada no incluye referencias a los materiales arqueológicos (Nocete et al., 211:3284) y por tanto no se les puede asignar momentáneamente

\begin{tabular}{|l|c|c|c|}
\hline Estadístico & VAlor & $\mathrm{df}$ & Sig. Asint. (2-colas) \\
\hline Chi-cuadrado de Pearson & 30,70 & 7 &, 00 \\
\hline Razón de semejanza & 32,28 & 7 &, 00 \\
\hline Asociación lineal & 8,15 & 1 &, 00 \\
\hline N. ${ }^{o}$ de casos válidos & 235 & & \\
\hline
\end{tabular}

FIG. 19. Resultados del análisis de Chi Cuadrado de Pearson [SPSS 22.0] para las categorías de la variable forma en relación con los estratos. atribución cultural. En el sector del nuevo Instituto de Enseñanza Secundariase han documentado estructuras con cronologías radiocarbónicas de hacia $1500 \mathrm{cal} \mathrm{AC}$ (Vargas et al., 2010: 3351; Nocete et al., 211:3284). Los materiales arqueológicos que se asocian a estos contextos, aún inéditos, podrán definir en su momento si estamos ante una ocupación del Bronce antiguo o ante evidencias más tardías, como sospechamos precisamente por esa fecha absoluta. Esta posibilidad de una ocupación posterior sin continuidad necesaria ha quedado reflejada también en la necrópolis de dicho asentamiento. Recordemos, a tal efecto, la 


\begin{tabular}{|c|c|c|c|c|c|}
\hline \multirow[b]{2}{*}{ Estrato } & \multicolumn{4}{|c|}{ DECORACIÓN } & \multirow[b]{2}{*}{ TOTAL } \\
\hline & 0 & 1 & 2 & 4 & \\
\hline \multirow[t]{2}{*}{1} & 64,00 & 9,00 & 4,00 & 5,00 & 82,00 \\
\hline & 74,32 & 3,49 & 1,40 & 2,79 & ,00 \\
\hline \multirow[t]{2}{*}{2} & 149,00 & 1,00 &, 00 & 3,00 & 153,00 \\
\hline & 138,68 & 6,51 & 2,60 & 5,21 &, 00 \\
\hline TOTAL & 213,00 & 10,00 & 4,00 & 8,00 & 235,00 \\
\hline
\end{tabular}

FIG. 20. Tabla de contingencia para las variables decoración y estrato. Para cada combinación posible entre las categorías de decoración y estratos aparecen dos valores: el superior es el recuento y el inferior es el valor esperado. Por ejemplo, para la decoración 0 en el estrato 1 se contabilizan 64 casos, mientras que el valor teórico esperado es 74,32.

\begin{tabular}{|l|c|c|c|}
\hline Estadístico & VALOR & df & Sig. Asint. (2-colas) \\
\hline Chi-cuadrado de Pearson & 25,72 & 3 &, 00 \\
\hline Razón de Semejanza & 26,51 & 3 &, 00 \\
\hline Asociación Lineal & 11,69 & 1 &, 00 \\
\hline N. ${ }^{\circ}$ de casos válidos & 235 & & \\
\hline
\end{tabular}

FIG. 21. Resultados del análisis de Chi Cuadrado de Pearson [SPSS 22.0] para las categorías de la variable decoración en relación con los estratos.
Carambolo. Este otro punto cuenta con una ocupación del Cobre anterior a la fundación del santuario fenicio (Ruiz Mata, 1978-79: 45-46), y con un pequeńo asentamiento posterior datado en el Bronce medio (Fernández Flores y Rodríguez Azogue, 2010: 214216). Los niveles calcolíticos y los posteriores del Bronce tampoco ofrecen en este caso una superposición tangente o secante. Sin relacionarse directamente, distan muy poco entre sí. Han sido sus materiales arqueológicos y sus radiodataciones los factores que han permitido ordenarlos cronológicamente.

En la margen opuesta del Guadalquivir, en la parte de la campińa sevillana bañada por el río Corbones, destaca en la comarca de Los Alcores el yacimiento de Carmona. Éste se localiza en una especie de atalaya natural que se convierte en un emplazamiento ideal en el que han convergido numerosas culturas a lo largo de la Historia. A pesar de que se conocen bien numerosos sitios donde se documentan las ocupaciones calcolíticas (Conlin, parasitación del hipogeo funerario de La Pastora reflejada por el hallazgo en sus inmediaciones del conjunto de puntas metálicas de jabalina que conserva el Museo Arqueológico de Sevilla. Algo parecido ocurre, dentro de la misma comarca sevillana del Aljarafe, en El
2006) y del Bronce (Jiménez, 2004) de Carmona, apenas existen estratigrafías con superposición de niveles de ambos periodos; y menos aún evidencias para mantener una continuidad cultural entre ambas edades. El primer caso con superposición de estratos

\begin{tabular}{|c|c|c|c|c|c|c|c|}
\hline ID_Lab & ID_Cau & Estrato & RCAYBP & Cal - 1 sigma & $\mathbf{p}^{*}=$ & Cal - 2 sigma & $\mathbf{p}^{*}=$ \\
\hline CNA166 & 9CAU-94-63 & Estrato I & $3660 \pm 50$ & 2057-1960 вС & 0.668 & $2146-1903$ вс & 0.964 \\
\hline CNA 160 & $3 \mathrm{CAU}-94-66$ & Estrato I & $3645 \pm 35$ & 2038-I952 вС & 0.867 & $2065-1922$ вс & 0.768 \\
\hline CNA 162 & $5 \mathrm{CAU}-94-65$ & Estrato I & $3635 \pm 30$ & 2032-I95I BC & 1.000 & 2050-1912 вс & 0.874 \\
\hline CNA 161 & $4 \mathrm{CAU}-94-65$ & Estrato I & $3575 \pm 45$ & I980-I88 I BC & 0.886 & $2034-1771$ вс & 1.000 \\
\hline CNA 164 & $7 \mathrm{CAU}-94-64$ & Estrato I & $3580 \pm 35$ & I974-I 888 вС & 0.992 & $2031-1876$ вС & 0.994 \\
\hline CNA 169 & $12 \mathrm{CAU}-94-60$ & Estrato II & $3545 \pm 35$ & I $94 \mathrm{I}-\mathrm{I} 876 \mathrm{BC}$ & 0.699 & $1976-1765$ вс & 0.994 \\
\hline CNA 165 & $8 \mathrm{CAU}-94-63$ & Estrato I & $3535 \pm 30$ & I923-I 874 BC & 0.546 & $1948-1767$ вс & 1.000 \\
\hline CNA 167 & $10 \mathrm{CAU}-94-61$ & Estrato II & $3505 \pm 45$ & I $888-\mathrm{I} 767 \mathrm{BC}$ & 1.000 & $1944-1735$ вс & 0.962 \\
\hline CNA 163 & $6 \mathrm{CAU}-94-64$ & Estrato I & $3515 \pm 30$ & I $847-\mathrm{I} 774 \mathrm{BC}$ & 0.770 & $1921-1751$ вс & 1.000 \\
\hline CNA 168 & $11 \mathrm{CAU}-94-61$ & Estrato II & $3485 \pm 35$ & I $878-\mathrm{I} 839 \mathrm{BC}$ & 0.374 & $1897-1734$ вС & 0.947 \\
\hline
\end{tabular}

* Probabilidad de distribución según Reimer et al., 2013.

FIG. 22. Resultados del conjunto de análisis radiocarbónicos efectuados. 


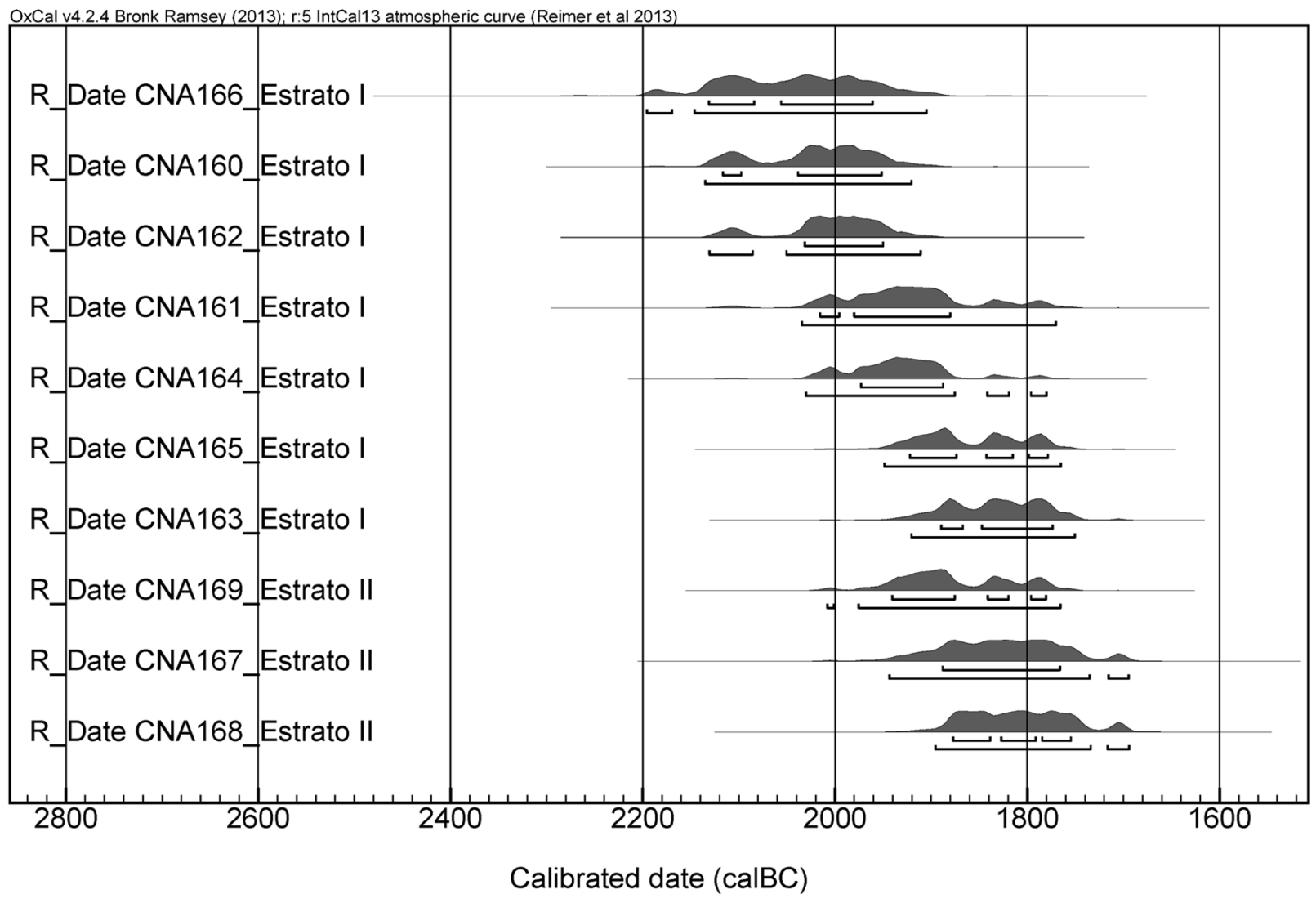

FIG. 23. Curvas de distribución de las calibraciones a 1 y 2 sigmas [Oxcal 4.2] de Coria del Río.

de dichos periodos se encuentra en el solar ubicado en Plaza de Santiago n. ${ }^{\circ}$ 1. Según los arqueólogos (Cardenete et al., 1992: 495 y ss.), se documentan aquí ocho unidades calcolíticas y seis posteriores del Bronce inicial-medio, todas ellas con una naturaleza deposicional lenta en un ambiente supuestamente próximo a zonas de hábitat. Sólo se ha documentado una estructura de forma acampanada y dimensiones y funcionalidad desconocidas excavada en el alcor, estructura que supone la primera actividad calcolítica de la estratigrafía. La única evidencia restante de posibles indicios de hábitat en el sitio se trata de “... grandes adobes caídos, piedras y un posible murete" (Cardenete et al., 1992: 495) en un estrato del Bronce. Pero entre éste y el nivel calcolítico superior existen otras cuatro unidades horizontales, lo que reduce notablemente las posibilidades de sostener una continuidad cultural por parte de las poblaciones de ambas fases. La segunda estratigrafía que conjuga niveles de ambos periodos también procede del Barrio de Santiago. Se trata "de tres sepulturas practicadas junto o sobre un foso... excavado en el alcor y colmatado en momentos avanzados de la Edad del Cobre" (Belén et al., 2000: 387), de forma que éste estaría abandonado y en desuso una vez se realizan los enterramientos del Bronce. La tercera estratigrafía con niveles de ambos contextos procede de una excavación reciente en un solar de Ronda del Cenicero. Aquí los estratos calcolíticos contienen todos cerámicas campaniformes, y existen algunas fosas así como un posible fondo de cabaña ${ }^{2}$. Los niveles del Bronce documentados se superponen a la roca geológica o a los estratos calcolíticos, si bien la mayoría se datan en diversos periodos avanzados,

2 Román Rodríguez, J. M. (2011): Excavación arqueológica preventiva en el solar de la calle Ronda del Cenicerol esquina San Teodomiro Bravo, Carmona (Sevilla). Memoria inédita depositada en el Servicio de Arqueología del Ayto. de Carmona, pp. 45 y ss. 
principalmente del Bronce final ${ }^{3}$. En la denominada Cuadrícula E se documenta parcialmente una fosa ovalada de grandes dimensiones y fondo plano. No dispone de niveles de uso, sino que está colmatada por vertidos ${ }^{4}$. El primero de ellos cuenta con un fragmento campaniforme y otro carenado con borde exvasado, posiblemente del Bronce final; el segundo se caracteriza por cazuelas carenadas del Bronce final.

En el extremo sur de Los Alcores, a pocos kilómetros del río Guadalquivir a la latitud de Sevilla, se encuentra la Mesa de Gandul (Alcalá de Guadaira), que muestra también una situación que podría ser parecida a la del Cerro de San Juan. Este enclave fue sondeado mediante la técnica Wheeler, por lo que es posible que algunos de sus niveles artificiales cuenten con elementos arqueológicos pertenecientes a estratos distintos. Aun así, sus excavadores distinguieron claramente una fase calcolítica identificada por los estratos X y Ix. Aunque el contexto que se superpone a esta etapa es ya protohistórico, se atribuyeron a un posible Bronce pleno ciertos "pequeños cuencos, finos y bruñidos" del Estrato Ix (Pellicer y Hurtado, 1987: 339). Al igual que en Valencina, el sector funerario de este asentamiento cuenta también con un reflejo directo de la secuencia ocupacional del poblado. De hecho, en torno al Tholos de las Canteras se alojaron covachas pequeñas subsidiarias del complejo megalítico. Estas tumbas responden a inhumaciones individuales del Bronce antiguo (Hurtado y Amores, 1984: 156). La asignación al 'Bronce pleno' de algunos materiales de la Mesa de Gandul se inserta en una problemática terminológica característica de los ańos ochenta del siglo pasado, cuando las excavaciones en Setefilla y en El Berrueco de Medina Sidonia revelaron la existencia de un Bronce genuino de Andalucía occidental (Serna et al., 1984), a la vez que echaban por tierra la posible pervivencia de los rasgos calcolíticos hasta época tartésica, como estaban proponiendo otros autores (Harrison et al., 1976: 86; Fernández Gómez y Alonso, 1985: 19-21). Con esta solución se eludía el problema de decidir si se trataba de un Bronce antiguo o de un Bronce medio, pues la documentación disponible entonces no permitía un diagnóstico mejor. Se seguían con ello algunas recomendaciones prudentes sobre el uso de unas asignaciones cronoculturales más precisas (Ruiz-Gálvez, 1984: 340).

\footnotetext{
3 Ibidem, p. 62.

4 Ibidem, pp. 62-63.
}

Más al s, Lebrija refleja más bien un caso parecido al del Carambolo. En el Cerro del Castillo, dentro del área nuclear del asentamiento antiguo de la ciudad, se originó primero una vieja aldea neolítica. Después de abandonado el hábitat, se usa de nuevo ese espacio concreto en tiempos campaniformes, aunque ahora como necrópolis. Y, tras una nueva desocupación, se instala allí un hábitat del Bronce medio con presencia de cerámica tipo Boquique (Caro et al., 1987: 169171; Escacena, 2011: 182).

En asentamientos algo más alejados del Guadalquivir, pero dentro de Andalucía occidental, destaca para esta fase el Monte Berrueco (Medina Sidonia, Cádiz). Una estratigrafía obtenida allí en 1982 reveló una secuencia cultural correspondiente al II milenio AC (Escacena y De Frutos, 1985). Los materiales cerámicos del Bronce antiguo y los enterramientos en el interior del hábitat, así como la presencia de un puñal metálico con enmangue de remaches, entre otros rasgos, sugirieron en su día la posibilidad de que el sitio fuera el producto del establecimiento en la campińa gaditana de grupos vinculados al mundo argárico (Escacena y Berriatúa, 1985). Por lo que se refiere al problema que ahora nos interesa, debe señalarse que el estrato más viejo del asentamiento no muestra materiales fechables necesariamente en la Edad del Cobre, aunque algunos platos muy planos recuerdan la tradición epicalcolítica. Por tanto, parece que la población del Bronce antiguo se instaló en un promontorio o en un sector de éste que no contaba con población previa. Es cierto que se localizó en el área excavada un fragmento de cerámica campaniforme, pero éste puede considerarse fácilmente un elemento residual debido a su posición estratigráfica, porque apareció entre la tierra de relleno de una pequeña fosa datada en el Bronce final-Hierro I (Escacena y Lazarich, 1990-91) (Fig. 24).

Al margen de estos escasos asentamientos que cuentan con estratos calcolíticos y del Bronce antiguo, existen fechas radiocarbónicas para otros sitios del Guadalquivir inferior con contextos arqueológicos adscritos sólo a uno de estos dos periodos (Fig. 24). La muestra de sitios disponible no es muy amplia, sobre todo si se compara con las dataciones existentes para ambos periodos arqueológicos en el SE peninsular. Sin embargo, aun con su carácter preliminar, puede advertirse que en algunas zonas de la región ambos repertorios arqueológicos pudieron solaparse cronológicamente. El intervalo temporal de 


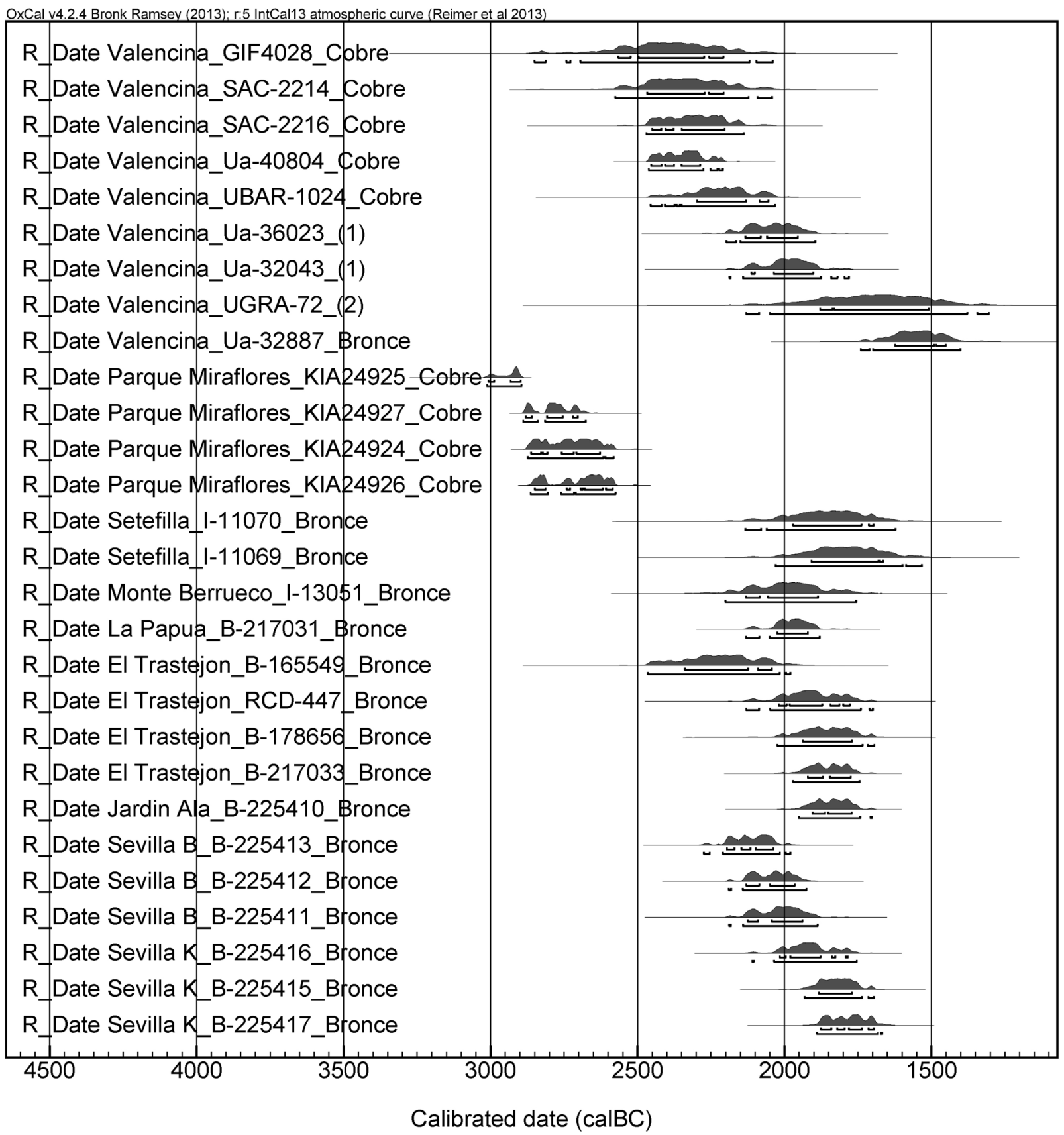

FIG. 24. Curvas de distribución de las calibraciones [Oxcal 4.2] de los sitios datados en el Calcolitico o Bronce antiguo del Guadalquivir inferior y áreas adyacentes. En el caso del yacimiento calcolitico de Valencina de la Concepción, se indican las fechas a partir de la mitad del III milenio a. C.; para el asentamiento del Bronce de El Trastejón se indican las cuatro fechas más tempranas disponibles. Notas aclaratorias: (1) Los arqueólogos no especifican información alguna sobre los contextos culturales de donde procede la muestra; (2) la publicación no aclara la procedencia estratigráfica de la muestra, más allá de señalar su profundidad (2 m). Referencias bibliográficas: 1 y 8) Castro Martinez et al., 1996; 2-3) Pajuelo y López, 2013; 4) Fernández y Aycart, 2013; 5) Sardá, 2013; 6, 7 y 9) Nocete et al., 2011; 8) Nocete et al., 2008; 10-13) Lara et al., 2004; 14-15) Aubet et al., 1983; 16) Escacena y De Frutos, 1986; 17-21) García Sanjuán y Hurtado, 2011; y 22-28) Hunt et al., 2008. 
esta posible coexistencia variará por supuesto dependiendo del análisis de las calibraciones y de sus intervalos por parte de cada investigador (Figs. 23 y 24).

\section{Conclusiones}

Según los resultados obtenidos en Cerro de San Juan de Coria del Río, así como en la revisión de los asentamientos bajoandaluces que acreditan la superposición Cobre-Bronce, no puede mantenerse el 'modelo de continuidad'; a día de hoy, es más fácil sostener el 'modelo de reemplazo'. Esto no quiere decir que toda la casuística acerca de la ocupación humana del occidente andaluz en la transición entre ambos periodos tuviese que haber sucedido en bloque bajo este único modelo, en el sentido de que se produjese un cambio demográfico único y homogéneo en todo el territorio. El 'modelo de reemplazo' explica la generalidad, lo que pudo ocurrir en la mayoría de los casos -explorados-. En consecuencia, ese modelo es el que el que conviene mantener como hipótesis de trabajo, que deberá estar siempre sujeta a pruebas, por supuesto.

La primera evidencia contundente en contra del 'modelo de continuidad' es el hecho de que es bajísimo el número de asentamientos que, de todos los conocidos para el Cobre y el Bronce de Andalucía occidental, cuentan con estratos de ambos periodos a la vez. La explicación más sencilla para este panorama es que, sea por la razón que sea, los emplazamientos calcolíticos quedaron en desuso, mientras que los sitios del Bronce se generaron ex novo, en lugares generalmente distintos a aquéllos. Esto explica que predomine la ausencia de un estrato fundacional atribuible al Calcolítico que preceda a la primera ocupación del Bronce. Así ocurre en la mayoría de poblados del Bronce antiguo conocidos en la actualidad. En el sureste peninsular está mejor documentada una situación similar: en torno al $2300 \mathrm{cal} \mathrm{AC}$, la mayor parte de los asentamientos calcolíticos se incendian y se abandonan; algunos presentan evidencias posteriores del Bronce antiguo, aunque con estructuras y modelos de hábitat muy distintos, pero la mayor parte de los sitios del Bronce antiguo se ubican en nuevos enclaves (Lull et al., 2010: 14).

Además, hay que anotar que los yacimientos mencionados donde se documenta superposición estratigráfica Cobre-Bronce tienen ciertas características comunes: emplazamientos sobre cerros y cabezos que dominan visualmente el paraje próximo; y en la mayoría de los casos jalonan la paleodesembocadura del Guadalquivir o el antiguo curso de otros ríos secundarios. Esto constituye una evidencia de que la ocupación de estos puntos en ambos periodos históricos se debe más a una mera convergencia que a una continuidad cultural demográfica. Es decir, algunos rasgos estratégicos de estos enclaves -topológicos, topográficos, etc.- los convierten en emplazamientos ideales para la ocupación humana, independientemente de la época de que se trate y de las circunstancias históricas de cada momento. Prueba de ello es la propia secuencia estratigráfica y cronológica de muchos de ellos, donde se documentan con frecuencia bastantes periodos históricos, desde la Prehistoria reciente hasta la actualidad.

Probablemente la característica recién señalada -la superposición de niveles en una misma estratigrafíahaya sido la variable más utilizada para defender la continuidad cultural y demográfica de diferentes periodos cronológicos no sólo en la arqueología andaluza sino cuanto menos en la española. Inicialmente esto es lógico. La perspectiva historicista promueve notablemente la idea de contemplar la superposición de estratos como el desarrollo continuado de la vida de una cultura -tradición-, mientras que la distribución espacial de la cultura material que la caracteriza se percibe como el marco geográfico de expansión de aquélla -horizonte-. El problema -ya se sabe- se origina a la hora de poner en común las historias (particularistas) de las diferentes culturas que interaccionan entre sí a lo largo del tiempo y espacio. En este sentido, deberíamos repensar si la superposición de estratos significa siempre continuidad cultural y demográfica, que es lo que parece haber dado por hecho la comunidad de arqueólogos andaluces. Esta visión, paradójicamente, se consolidó aún más desde la década de los setenta del s. xx, cuando ya emergían otras corrientes epistemológicas diferentes de las historicistas. Se trató de una tendencia marcada por el impulso autoctonista y por el rechazo de la difusión como mecanismo explicativo del cambio cultural.

La continuidad cultural de unas mismas poblaciones -en este caso, en la transición Cobre-Broncetal vez requeriría, por ejemplo, del uso continuado de espacios de hábitat y estructuras arquitectónicas, cosa que no se observa en ninguna de las estratigrafías analizadas. Es más, aun cuando se produjese la 
reutilización de un mismo ámbito arquitectónico, la continuidad democultural no siempre está garantizada. Póngase como ejemplo la reutilización histórica de edificios, religiosos o no, por parte de grupos étnicos diferentes con sólo la incorporación de algunos elementos simbólicos nuevos. La Mezquita de Córdoba, la Alhambra de Granada o la Giralda sevillana, entre otros muchos casos, suponen ejemplos paradigmáticos; y pueden añadirse a éstos casi todas las fortificaciones históricas.

Al margen del estudio estratigráfico, es importante el análisis comparativo de otros muchos rasgos arqueológicos entre los dos periodos considerados: por ejemplo, tecnologías cerámica, lítica y metálica, pautas simbólicas, ritos funerarios, patrones de asentamiento, sistemas económicos, etc. A pesar de que se ha defendido la continuidad de la tecnología metalúrgica y de los productos de cobre desde la Edad del Cobre a la del Bronce (Caro, 1988-89: 235), hoy se acepta una transformación importante en la manipulación y gestión de los procesos metalúrgicos entre ambas etapas, si bien ese cambio se ha querido explicar mediante adaptaciones autónomas a los nuevos caracteres de la urbanística argárica (Montero-Ruiz y Murillo-Barroso, 2010: 39). Respecto a estas opiniones opuestas, lo cierto es que los principales repertorios que reúnen objetos metálicos de esta fase, por ejemplo los referidos a las puntas de tipo Palmela (Lazarich, 2005b), sólo recogen hojas metálicas de esa clase en contextos calcolíticos, siendo una de las pocas excepciones a esta regla el pedicelo de una de ellas localizado en la tumba 2 de la necrópolis de cistas de Las Mesas, en Gibraleón (Huelva) (Del Amo, 1975: 155 y lám. 112, 2). En el caso del instrumental lítico más exclusivo del Campaniforme, como los brazales de arquero, también son escasas las evidencias de que su uso fuera algo común entre las sociedades del Bronce antiguo del so. Aunque una pieza de este tipo procede de un contexto del Bronce antiguo de Setefilla, donde apareció rota, dicho ejemplar no pertenece a los enterramientos de esa fase inicial del poblado (Aubet et al., 1983: 57 y fig. 16, 13). Recuérdese a este respecto que el ámbito funerario es el más frecuente para hallazgos de este tipo en el Campaniforme. Esto explica, sin embargo, que los brazales de arquero no aparezcan tampoco en las cistas onubenses.

Otros muchos caracteres arqueológicos exhiben igualmente fuertes diferencias entre ambos periodos. Los patrones de asentamientos son parcialmente distintos en cuanto a las zonas de ocupación preferentes, pero difieren notablemente en la densidad de hábitats y en el tamaño de éstos, más escasos, pequeños y alejados entre sí en el Bronce antiguo. Los sistemas económicos son asimismo disímiles, con un espectro más reducido, principalmente pastoril, para dicho periodo. Las expresiones simbólicas, tan numerosas y diversas en la Edad del Cobre, apenas existen en el Bronce antiguo. Por último, los ritos funerarios son completamente distintos entre ambos periodos: esencialmente estructuras de enterramientos múltiples en la época calcolítica -fosas, cuevas artificiales, megalitos, etc.- e inhumaciones individuales -fosas, cistas y covachas- en la del Bronce.

Por tanto, y en resumen, el análisis realizado en este trabajo, así como el resto de evidencias señaladas relacionadas con la transición histórica entre los denominados periodos de la Edad del Cobre y de la Edad del Bronce, demuestran que el 'modelo de continuidad' ha de rechazarse por el momento. Al contrario, casi todas las evidencias parecen alinearse coherentemente con el 'modelo de reemplazo', el cual sostiene un fuerte cambio cultural entre ambos periodos que seguramente quede parsimoniosamente explicado con la hipótesis de que, en el ámbito bajoandaluz, las poblaciones del Bronce no son herederas directas de las calcolíticas.

No obstante, a juzgar por el panorama de las dataciones disponibles, este reemplazo de poblaciones no tuvo por qué contar con un hiato de desocupación intermedio. Puede inferirse que las poblaciones de ambos periodos, con sus respectivos bagajes culturales tan distintos, fueron coetáneas durante algún tiempo, de modo que pudieron producirse ciertos contactos entre ellas. Tal vez la presión entre ambas podría haber influido en el cambio cultural que se percibe en el registro arqueológico y por extensión en la sustitución de unas por otras.

Sea cual sea el factor principal preciso que explique este episodio de cambio histórico, tarea que excede el objetivo de este trabajo, la conclusión fundamental que sostiene nuestra lectura de los datos es la propuesta de un modelo de reemplazo tipo puzle. Éste sugiere un escenario antropológico con comunidades humanas distintas que, con su natural diversidad interna a lo largo de sus poblaciones, coexistieron, entraron en contacto -generando un registro arqueológico parcialmente variable en términos espaciales y cronológicos- y acabaron sustituyéndose entre sí. 


\section{Bibliografía}

Arteaga, O.; Schulz, H. D. y Roos, A. M. (1995): “El problema del Lacus Ligustinus. Investigaciones geoarqueológicas en torno a las Marismas del Bajo Guadalquivir”. En Tartessos 25 años después, 1968-1993. Jerez de la Frontera: Ayto. Jerez de la Frontera, pp. 99-135.

Aubet, M. E. y Serna, M. R. (1981): "Una sepultura de la Edad del Bronce en Setefilla (Sevilla)", Trabajos de Prehistoria, 38, pp. 225-251.

Aubet, M. E.; Serna, M. E.; Escacena, J. L. y Ruiz, M. M. (1983): La Mesa de Setefilla. Excavaciones Arqueológicas en España, 122. Madrid: Ministerio de Cultura.

Belén, M.; Anglada, R.; Conlin, E.; Gómez, T. y JiméNeZ, A. (2000): "Expresiones funerarias de la Prehistoria reciente de Carmona (Sevilla)", Spal, 9, pp. 385-403.

Bellin, N.; Vanacker, V. y De Baets, S. (2013): "Anthropogenic and climatic impact on Holocene sediment dynamics in SE Spain: A review", Quaternary International, 308-309, pp. 112-129.

http://dx.doi.org/10.1016/j.quaint.2013.03.015

BorJa, F. (2013): "La desembocadura del Guadalquivir en la segunda mitad del Holoceno". En García Sanjuán, L.; Vargas, J. M.; Hurtado, V.; Cruz-Auñón, R. y Ruiz Moreno, T. (coords.): El asentamiento prehistórico de Valencina de la Concepción (Sevilla): Investigación y tutela en el 150 aniversario del descubrimiento de La Pastora. Sevilla: Univ. Sevilla, pp. 93-112.

Bronk Ramsey, C. (2009): "Bayesian analysis of radiocarbon dates", Radiocarbon, 51 (1), pp. 337-360.

Cáceres, L. M.; Muñiz, F.; Rodríguez, J.; Vargas, J. M. y Donaire, T. (2014): "Marine bioerosion in rocks of the prehistoric tholos of La Pastora (Valencina de la Concepción, Seville, Spain): archaeological and palaeoenvironmental implications", Journal of Archaeological Science, 41, pp. 435-446.

http://dx.doi.org/10.1016/j.jas.2013.09.001

Cacho, I.; Valero, B. y González Sampériz, P. (2010): “Revisión de las reconstrucciones paleoclimáticas en la Península Ibérica desde el último periodo glacial”. En Pérez, F. F. y Boscolo, R. (eds.): Clima en España: Pasado, presente y futuro. Informe de Evaluación del Cambio Climático Regional. Red Temática CLIVAR-España, pp. 9-24.

Cardenete, R.; Gómez, M. T.; Jiménez, A.; Lineros, R. y Rodríguez, I. (1992): "Excavaciones arqueológicas de urgencia en el solar de la Plaza de Santiago n. ${ }^{\circ}$ ", Anuario Arqueológico de Andalucía 1990, (3), pp. 488-497. Sevilla.

Caro, A. (1988-89): "Los inicios del II milenio a. C. en el Bajo Guadalquivir: el tránsito del Cobre al Bronce”, Zephyrus, XLI-XLII, pp. 229-239.

Castro, P. V.; Lull, V. y Micó, R. (1996): Cronología de la Prehistoria reciente de la Peninsula Ibérica y Baleares (c. 2800900 (al ANE). BAR Int. Ser., 652. Oxford: Tempvs Reparatum.
Chapman, R. (1990): Emerging complexity: the Late Prehistory of South-East Spain, Iberia, and the West Mediterranean. Cambridge: cup. http://dx.doi.org/10.1017/CBO9780511735486

Conlin, E. (2006): "Acerca del origen verdadero de Carmona: Su secuencia evolutiva en la Edad del Cobre", Carel. Revista de Estudios Locales de Carmona, 4, pp. 1608-1640.

Del Amo, M. (1975): "Enterramientos en cista de la provincia de Huelva”. En Almagro, M. (dir.): Huelva: Prehistoria y Antigüedad. Madrid: Editora Nacional, pp. 109-182.

EsCACENA, J. L. (2011): "La primera fundación de Lebrija y el poblamiento neolítico de la antigua ensenada bética". En Abellán, J.; Lazarich, C. y Castañeda, V. (dirs.): Homenaje al Profesor Antonio Caro Bellido. I, Prehistoria y Protohistoria de Andalucía y Levante. Cádiz: Univ. Cádiz, pp. 171-203.

Escacena, J. L. y Berriatúa, N. (1985): “El Berrueco de Medina Sidonia (Cádiz). Testimonios de una probable expansión argárica hacia el Oeste", Cuadernos de Prehistoria de la Universidad de Granada, 10, pp. 225-242.

Escacena, J. L. y De Frutos, G. (1981-82): "Enterramientos de la Edad del Bronce del Cerro del Berrueco (Medina Sidonia, Cádiz)", Pyrenae, 17-18, pp. 165-190.

Escacena, J. L. y De Frutos, G. (1985): "Estratigrafía de la Edad del Bronce en el Monte Berrueco (Medina Sidonia, Cádiz)", Noticiario Arqueológico Hispánico, 24, pp. 7-90.

Escacena, J. L. y De Frutos, G. (1986): "El tránsito del Calcolítico al Bronce a través del 'Monte Berrueco' de Medina Sidonia (Cádiz)", Trabajos de Prehistoria, 43, pp. 61-84.

Escacena, J. L. e Izquierdo, R. (1999): "Proyecto Estuario. Intervención arqueológica de 1994", Anuario Arqueológico de Andalucia 1994. II, Actividades Sistemáticas, pp. 161-166. Sevilla.

Escacena, J. L. e Izquierdo, R. (2001): “Oriente en Occidente. Arquitectura civil y religiosa en un barrio fenicio de la Caura tartésica”. En Ruiz Mata, D. y Celestino, S. (eds.): Arquitectura Oriental y Orientalizante en la Peninsula Ibérica. Centro de Estudios del Próximo Oriente. Madrid: csic, pp. I23-I 57.

Escacena, J. L. y LaZarich, M. (1990-91): "A propósito del campaniforme del Berrueco de Medina Sidonia y del problema de su posición estratigráfica”. En Homenaje póstumo a A. Holgado Redondo. Anales de la Univ. Cádiz, vII-VIII, t. I, pp. 177-201.

Fernández Flores, A. y Aycart, V. (2013): "Montelirio. Un sepulcro clave para la comprensión del registro de los grandes monumentos megalíticos". En García Sanjuán, L.; Vargas, J. M.; Hurtado, V.; Cruz-Auñón, R. y Ruiz Moreno, T. (coords.): El asentamiento prehistórico de Valencina de la Concepción (Sevilla): Investigación y tutela en el 150 aniversario del descubrimiento de La Pastora. Sevilla: Univ. Sevilla, pp. 233-259. 
Fernández Flores, A. y Rodríguez Azogue, A. (2010): “El Carambolo, secuencia cronocultural del yacimiento. Síntesis de las intervenciones 2002-2005”. En De LA BANDERA, M. L. y Ferrer, E. (coords.): El Carambolo. 50 años de un tesoro. Sevilla: Univ. de Sevilla, pp. 203-270.

Fernández Gómez, F. y Alonso, J. (1985): "Un fondo de cabaña campaniforme en la Universidad Laboral de Sevilla”, Noticiario Arqueológico Hispánico, 22, pp. 7-26.

Fernández Gómez, F.; Guerrero, L. J.; Ventura, J. J.; De la Hoz, A.; Alonso, J.; Alcázar, J. y Suárez, A. (1997): Orippo en la Antigüedad. Las excavaciones arqueológicas de 1979 a 1983. Dos Hermanas: Ayto. Dos Hermanas.

Fernández Gómez, F; Ruiz Mata, D. y Sancha, S. (1976): "Los enterramientos en cista del Cortijo de Chichina (Sanlúcar la Mayor, Sevilla)”, Trabajos de Prehistoria, 33, pp. 351-386.

García Rivero, D. (2005): "Prehistoria y evolución: reflexiones sobre la secuencia ecológico-cultural holocénica en el mediodía ibérico", Spal, 13, pp. 9-34. http://dx.doi.org/10.12795/spal.2004.i13.01

García Rivero, D. (2007): "Campaniforme y territorio en la Cuenca Media del Guadiana”, Spal, 15, pp. 71-102.

García Rivero, D. (2008): Campaniforme y rituales estratégicos en la Cuenca Media y Baja del Guadiana (Suroeste de la Peninsula Ibérica).BAR, 1837. Oxford: Archaeopress.

García Rivero, D. (2009): “Campaniforme, jerarquización social y selección interdémica en el Suroeste de la Península Ibérica. Una aproximación desde la Arqueología evolutiva”. En Cruz-Auñón, R. y Ferrer, E. (coords.): Estudios de Prehistoria y Arqueología en Homenaje a P. Acosta Martinez. Sevilla: Univ. Sevilla, pp. 233-254.

García Sanjuán, L. y Hurtado, V. (2011): "Las dataciones absolutas de El Trastejón en el marco de la cronología absoluta de la Edad del Bronce (c. 2200-850 CAL ANe) en el sur de la Península Ibérica”. En Hurtado, V.; García Sanjuán, L. y Hunt, M. (coords.): El asentamiento de El Trastejón (Huelva). Investigaciones en el marco de los procesos sociales y culturales de la Edad del Bronce en el suroeste de la Peninsula Ibérica. Sevilla: Junta de Andalucía, pp. 138-166.

Gavala, J. (1959; 1992 ed. facs.): La geología de la costa y bahía de Cádiz y el poema "Ora Maritima”, de Avieno. Cádiz: Diput. Prov. Cádiz.

Gavilán, B. y Escacena, J. L. (2009): “Acerca del primer Neolítico de Andalucía occidental. Los tramos medio y bajo de la cuenca del Guadalquivir", Mainake, xxxı, pp. 311-351.

Harding, A. F. (2003): Sociedades europeas en la Edad del Bronce. Barcelona: Ariel.

Harris, E. C. (1991): Principios de estratigrafía arqueológica. Barcelona: Crítica.

Harrison, R. J. y Moreno, G. (1985): "El policultivo ganadero o la revolución de los productos secundarios", Trabajos de Prehistoria, 42, pp. 51-82.
Harrison, R. J.; Bubner, T. y Hibbs, V. (1976): “The beaker pottery from El Acebuchal, Carmona (prov. Sevilla)", $M a-$ drider Mitteilungen, 17, pp. 79-141.

Hunt, M. (coord.) (2012): Intervenciones arqueológicas en el área del proyecto minero Cobre Las Cruces (1996-2011): de la Prehistoria a la Época Contemporánea (provincia de Sevilla, España). Sevilla: Fund. Cobre Las Cruces.

Hunt, M.; Vázquez, J.; García Rivero, D. y Pecero, J. C. (2008): "Dataciones radiocarbónicas de necrópolis del Bronce en el entorno del Bajo Guadalquivir". En Rovira, S.; García-Heras, M.; Gener, M. y Montero, I. (eds.): Actas del VII Congreso Ibérico de Arqueometría. Madrid: CSIC, pp. 226-234.

Hurtado, V. y Amores, F. (1984): "El tholos de Las Canteras y los enterramientos del Bronce en la Necrópolis de El Gandul (Alcalá de Guadaira, Sevilla)", Cuadernos de Prehistoria de la Universidad de Granada, 9, pp. 147-174.

Hurtado, V.; García Sanjuán, L. y Hunt, M. (coords.) (2011): El asentamiento de El Trastejón (Huelva). Investigaciones en el marco de los procesos sociales y culturales de la Edad del Bronce en el suroeste de la Peninsula Ibérica. Sevilla: Junta de Andalucía.

JimÉnEz, A. (2004): "La secuencia cultural del II milenio a. C. en Los Alcores (Sevilla)", Carel. Revista de Estudios Locales de Carmona, 2, pp. 425-590.

Lara, D. A.; Barragán, D. y Garrido, M. (2004): "El asentamiento calcolítico del Parque de Miraflores (Sevilla): resultados preliminares", Spal, 13, pp. 245-255. http://dx.doi.org/10.12795/spal.2004.i13.09

Lazarich, M. (1999): El Campaniforme en Andalucia Occidental. Cádiz: Univ. Cádiz.

LAZARich, M. (2005a): "El campaniforme en Andalucía”. En Rojo, M. A.; Garrido, R. y García, I. (coords.): El campaniforme en la Península Ibérica y su contexto europeo. Valladolid: Univ. Valladolid, pp. 351-370.

LAZARICH, M. (2005b): "La producción metalúrgica del II milenio a. C. en la baja Andalucía: las puntas de tipo 'Palmela", Almajar, 2, pp. 29-38.

Lull, V.; Micó, R.; Rinuete, C. y Risch, R. (2010): "Las relaciones políticas y económicas de El Argar”, Menga, 1, pp. 11-36.

Martín-Puertas, C.; Valero-Garcés, B. L.; Mata, M. P.; González-Sampériz, P.; Bao, R.; Moreno, A. y SteFANOVA, V. (2008): "Arid and humid phases in southern Spain during the last 4000 years: the Zonar lake record, Córdoba”, The Holocene, 18 (6), pp. 907-921. http://dx.doi.org/10.1177/0959683608093533

Mederos, A. (1996): "La cronología absoluta de Andalucía occidental durante la Prehistoria reciente (6100-850 AC)", Spal, 5, pp. 45-86. http://dx.doi.org/10.12795/spal.1996.i5.03

Menanteau, L. (1982): Les Marismas du Guadalquivir, exemple de transformation d'un paysage alluvial au cours du Quaternaire récent. Paris: Univ. Paris-Sorbonne. 
Montero-Ruiz, I. y Murillo-Barroso, M. (2010): “La producción metalúrgica en las sociedades argáricas y sus implicaciones sociales: una propuesta de investigación", Menga, 1, pp. 37-51.

Morales, A. (1986): "Informe faunístico del yacimiento. Corte C-4.3. Fondo n. 3. Sector C". En Martín de la Cruz, J. C. (ed.): Papa Uvas II. Aljaraque, Huelva. Campañas de 1981 a 1983. Excavaciones Arqueológicas en España, 149. Madrid, pp. 345-350.

Nocete, F.; Queipo, G.; Sáez, R.; Nieto, J. M.; Inacio, N.; Rodríguez, M.; Peramo, A.; Vargas, J. M.; CruzAuñón, R.; Gil-Ibarguchi, J. I. y Santos, J. F. (2008): "The smelting quarter of Valencina de la Concepción (Seville, Spain): the specialised copper industry in a political centre of the Guadalquivir valley during the third millennium вС (2750-2500)", Journal of Archaeological Science, 35, pp. 717-732.

http://dx.doi.org/10.1016/j.jas.2007.05.019

Nocete, F.; Sáez, R.; Rodríguez, M.; Péramo, A.; Inacio, N. y Abril, D. (2011): "Direct chronometry (14C AMs) of the earliest copper metallurgy in the Guadalquivir Basin (Spain) during the third millennium вC: first regional database", Journal of Archaeological Science, 38 (12), pp. 3278-3329. http://dx.doi.org/10.1016/j.jas.2011.07.008

Padilla. A. (1993): "Caura: el topónimo". En Escacena, J. L. (coord.): Arqueología de Coria del Río y su entorno. Azotea, 11-12. Monográfico de la Revista de Cultura del Ayto. de Coria del Río, pp. 63-64.

Pajuelo, A. y López, P. M. (2013): "Estudio arqueozoológico de estructuras significativas de c/ Mariana de Pineda, s/n (Valencina de la Concepción, Sevilla)”. En García SANjuán, L.; Vargas, J. M.; Hurtado, V.; Cruz-Auñón, R. y Ruiz Moreno, T. (coords.): El asentamiento prehistórico de Valencina de la Concepción (Sevilla): Investigación y tutela en el 150 aniversario del descubrimiento de La Pastora. Sevilla: Univ. Sevilla, pp. 445-458.

Pellicer, M. y Hurtado, V. (1987): "Excavaciones en la Mesa de El Gandul (Alcalá de Guadaira, Sevilla)". En Anuario Arqueológico de Andalucíal1986. II, Actividades Sistemáticas. Sevilla, pp. 338-341.

PÉrez Macías, J. A. (1997): “Anotaciones sobre el Bronce del Suroeste. Necrópolis de cistas en el entorno del embalse de Aracena”, Huelva en su Historia, 6, pp. 9-30.

Pozo, F. y Tabales, M. A. (1991): "Intervención arqueológica de apoyo a la restauración en el Castillo de Alcalá de Guadaíra”. En Anuario Arqueológico de Andalucial1989. III, Actividades de Urgencia. Sevilla, pp. 536-545.
Ramos, J. (1993): El hábitat prehistórico de 'El Estanquillo', San Fernando. San Fernando: Ayto. San Fernando.

Reimer, P. J.; Bard, E.; Bayliss, A.; Beck, J. W.; Blacwell, P. G.; Bronk Ramsey, C.; Grootes, P. M.; Guilderson, T. P.; Haflidason, H.; Hajdas, I.; Hatt, C.; Heaton, T. J.; Hoffman, D. L.; Hogg, A. G.; Hughen, K. A.; KaISer, K. F.; Kromer, B.; Manning, S. W.; NiU, M.; ReImer, R. W.; Richards, D. A.: Scott, E. M.; Southon, J. R.; Staff, R. A.; Turney, C. S. M. y Van der Plicht, J. (2013): "IntCal13 and Marine13 Radiocarbon age calibration curves 0-50,000 years cal вР", Radiocarbon, 55 (4), pp. 1869-1887. http://dx.doi.org/10.2458/azu_js_rc.55.16947

Ruiz Mata, D. (1975a): "Cerámicas del Bronce del poblado de Valencina de la Concepción (Sevilla): los platos", Cuadernos de Prehistoria y Arqueología de la UAM, 2, pp. 123-149.

Ruiz Mata, D. (1975b): “Cerámicas del Bronce del poblado de Valencina de la Concepción (Sevilla)", Madrider Mitteilungen, 16, pp. 80-110.

Ruiz Mata, D. (1978-79): "Nuevos yacimientos campaniformes en la provincia de Sevilla", Cuadernos de Prehistoria y Arqueología de la UAM, 5-6, pp. 41-57.

Ruiz-GÁlvez, M. (1984): "Reflexiones terminológicas en torno a la Edad del Bronce peninsular", Trabajos de Prehistoria, 41, pp. 323-342.

SARDÁ, D. (2013): "Estructuras negativas multifuncionales en Avda. de Andalucía n. ${ }^{\circ}$ 9, Valencina de la Concepción (Sevilla)". En García Sanjuán, L.; Vargas, J. M.; Hurtado, V.; Cruz-Auñón, R. y Ruiz Moreno, T. (coords.): El asentamiento prehistórico de Valencina de la Concepción (Sevilla): Investigación y tutela en el 150 aniversario del descubrimiento de La Pastora. Sevilla: Univ. Sevilla, pp. 151-156.

Serna, M. R.; Escacena, J. L. y Aubet, M. E. (1984): "Nuevos datos para una definición del Bronce Antiguo y Pleno en el Bajo Guadalquivir". En Waldren, W. H.; Chapman, R.; Lewthwaite, J. y Kennard, R. C. (eds.): The Deya Conference of Prehistory: Early Settlement in the Western Mediterranean Islands and the Peripheral Areas. BAR Int. Ser., 229. Oxford: Archaeopress, pp. 1051-1073.

VAlera, A. C. (2006): "A margem esquerda do Guadiana (região de Mourão) dos finais do $4^{\circ}$ a os inícios do $2^{\circ}$ milênio AC", Era-arqueologia, 7, pp. 136-210.

Vargas, J. M.; Nocete, F. y Ortega, M. (2010): “Excavaciones arqueológicas en la parcela del nuevo ies de Valencina de la Concepción, Sevilla”. En Anuario Arqueológico de Andalucía 2005. Sevilla, pp. 3340-3356. 